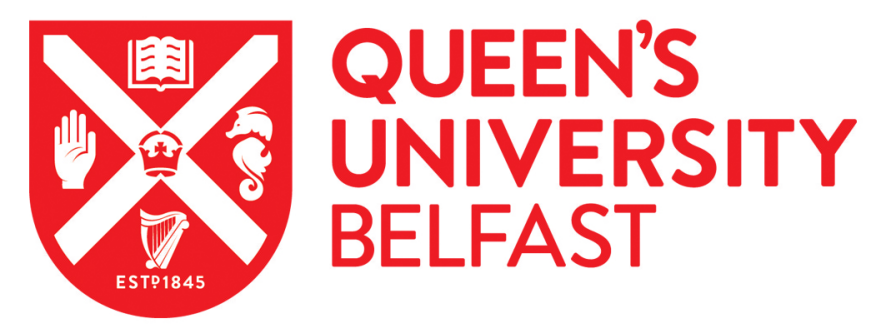

\title{
Increased expression of bronchial epithelial transient receptor potential vanilloid 1 channels in severe asthma
}

\author{
McGarvey, L. P., Butler, C. A., Stokesberry, S., Polley, L., McQuaid, S., Abdullah, H., Ashraf, S., McGahon, M. \\ K., Curtis, T. M., Arron, J., Choy, D., Warke, T. J., Bradding, P., Ennis, M., Zholos, A., Costello, R. W., \& \\ Heaney, L. G. (2014). Increased expression of bronchial epithelial transient receptor potential vanilloid 1 \\ channels in severe asthma. Journal of Allergy and Clinical Immunology, 133(3), 704-712. \\ https://doi.org/10.1016/j.jaci.2013.09.016 \\ Published in: \\ Journal of Allergy and Clinical Immunology
}

Document Version:

Peer reviewed version

Queen's University Belfast - Research Portal:

Link to publication record in Queen's University Belfast Research Portal

\section{Publisher rights}

Copyright 2014 Elsevier

This manuscript is distributed under a Creative Commons Attribution-NonCommercial-NoDerivs License

(https://creativecommons.org/licenses/by-nc-nd/4.0/), which permits distribution and reproduction for non-commercial purposes, provided the author and source are cited.

\section{General rights}

Copyright for the publications made accessible via the Queen's University Belfast Research Portal is retained by the author(s) and / or other copyright owners and it is a condition of accessing these publications that users recognise and abide by the legal requirements associated with these rights.

Take down policy

The Research Portal is Queen's institutional repository that provides access to Queen's research output. Every effort has been made to ensure that content in the Research Portal does not infringe any person's rights, or applicable UK laws. If you discover content in the Research Portal that you believe breaches copyright or violates any law, please contact openaccess@qub.ac.uk. 
Elsevier Editorial System(tm) for Journal of Allergy and Clinical Immunology Manuscript Draft

Manuscript Number: JACI-D-13-00335R1

Title: Increased expression of bronchial epithelial transient receptor potential vanilloid 1 channels in severe asthma

Article Type: Original Article

Section/Category: Asthma and Lower Airway Disease

Keywords: ion channel; sensory; severe asthma; irritant; chemical; exacerbation; cough

Corresponding Author: Dr. Lorcan McGarvey, MD

Corresponding Author's Institution: Queen's University Belfast

First Author: Lorcan P McGarvey, MD

Order of Authors: Lorcan P McGarvey, MD; Claire A Butler, PhD; Susan Stokesberry, PhD; Liam Polley, MD; Stephen McQuaid, PhD; Hanni'ah Abdullah, PhD; Sadaf Ashraf, PhD; Mary K McGahon, PhD; Tim M Curtis, PhD; Joe Arron, MD, PhD; Dave Choy, BSc; Tim J Warke, MD; Peter Bradding, DM; Madeleine Ennis, PhD; Alex Zholos, PhD; Richard W Costello, MD; Liam G Heaney, MD

Manuscript Region of Origin: UNITED KINGDOM

Abstract: Background: The airway epithelium is exposed to a range of physical and chemical irritants in the environment which are known to trigger asthma. Transient Receptor Potential (TRP) cation channels play a central role in sensory responses to noxious physical and chemical stimuli. Recent genetic evidence suggests an involvement of TRPV1, one member of the vanilloid subfamily of TRP channels, in the pathophysiology of asthma. The functional expression of TRPV1 on airway epithelium has yet to be elucidated.

Objective: In this study we examined the molecular, functional and immunohistochemical expression of TRPV1 in the asthmatic and healthy airway.

Methods: Bronchial biopsies and bronchial brushings were obtained from healthy volunteers $(\mathrm{n}=18)$, mild to moderate asthmatics $(n=24)$ and refractory asthmatics $(n=22)$. To investigate the functional role of TRPV1, cultured primary bronchial epithelial cells (PBEC) from mild asthmatics ( $n=4)$, non asthmatic coughers $(n=4)$ and healthy subjects $(n=4)$ were studied.

Results: Quantitative immunohistochemistry revealed significantly more TRPV1 expression in asthmatics compared to healthy subjects and with greatest expression in the refractory asthmatics $(\mathrm{p}=0.001)$. PCR and Western blotting analysis confirmed gene and protein expression of TRPV1 in cultured primary bronchial epithelial cells (PBEC). Patch-clamp electrophysiology directly confirmed functional TRPV1 expression in all three groups. In functional assays, the TRPV1 agonist capsaicin induced dose dependent interleukin-8 (IL-8) release which could be blocked by the antagonist capsazepine. Reduction of external pH from 7.4 to 6.4 activated a capsazepine-sensitive outwardlyrecifiying membrane current.

Conclusions: Functional TRPV1 channels are present in the human airway epithelium and are overexpressed in the airways of refractory asthmatics. These channels may represent a novel therapeutic target for uncontrolled asthma. 



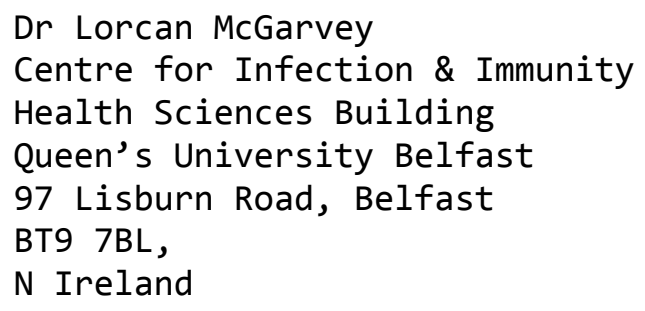

To The Editors

Journal of Allergy and Clinical Immunology

$15^{\text {th }}$ August 2013

Dear Editors,

Many thanks for the opportunity to respond to the reviewers comments and to submit a revised manuscript. We found each of the comments extremely helpful and based on these have undertaken a number of additional experiments which we and believe have resulted in an improved manuscript. We have provided our response to the specific comments from the Editor and each of the reviewers' comments below and indicated where changes have been made to the manuscript

SPECIFIC COMMENTS FROM THE EDITOR:

Although your submission is intriguing, there are issues regarding specificity of the cell types studied, sample size for some of the assessments, and examination of the impact of leukotrienes; these must be addressed.

RESPONSE: We are pleased that the Editor finds our manuscript intriguing. We have undertaken additional experiments to address the issue regarding cell specificity and addressed the important issue of studying more specific environmental irritants in particular the effect of acidic $\mathrm{pH}$. We have also considered and responded to the comment regarding leukotrienes.

We have also reduced the length of article to meet with the request to restrict length to 7 pages and reduced the figure legend word count where possible to fewer than 60 words.

COMMENTS FROM REVIEWER \#1:

General Comments

I thought that the methodology was sound in this manuscript. My major questions center on following numbers of subjects done for each assay, which made the manuscript more difficult to follow.

RESPONSE: We thank the reviewer for this positive comment and we are pleased they believe our methodology to be 'sound'. We have carefully addressed each of the specific comments below to provide clarification on 'number of subjects done for each assay’.

Specific Comments

1) It is unclear why there are two separate cohorts of patients---the Belfast and Leicester. I was unclear how many from each group had IHC and gene expression assays. Did the same subjects have microarray, qPCR and IHC, or did only the Leicester cohort have microarray and the IHC 
was done from subjects from Belfast---this was difficult to follow in the manuscript.

RESPONSE: We apologise for the lack of clarity. IHC was performed on the Belfast Cohort only and the microarray and GPCR was performed only on the freshly isolated brushings from Leicester cohort. We have now clarified this in our methods section and have indicated the number of subjects (see methods section revised manuscript (Marked), page 8 , line 17-20)

2) How were subjects with possible COPD excluded? In table 1, the pack year range was 1-20 years. Or does it not matter that this group with severe asthma may have included not "pure asthma."

RESPONSE: Data from this cohort has been published previously. (Shikotra A et al. Increased expression of immunoreactive thymic stromal lymphopoietin in patients with severe asthma. J Allergy Clin Immunol. 2012 Jan;129(1):104-11 and Butler CA et al. Glucocorticoid receptor $\beta$ and histone deacetylase 1 and 2 expression in the airways of severe asthma. Thorax. 2012 May;67(5):392-8). A great strength of the cohort is that the patients are well characterised in specialist centres with regard to diagnosis, physiology and adherence with therapy and all fulfil the definition of severe refractory asthma. The median pack year history is only 2.5 years and in an analysis of ex-smokers, we have also recently demonstrated that ex-smokers with a $<10$ pack year history have broadly similar demographic and inflammatory profiles to never smokers with severe asthma (Thomson NC et al. Clinical outcomes and inflammatory biomarkers in current smokers and ex-smokers with severe asthma. J Allergy Clin Immunol. 2013 Apr;131(4):1008-16) and so we believe that the smoking history does not affect the conclusions from this study.

3) Were subjects in Table 2 also included in Table 1? Table 2 also should read "mild asthma" instead of cough variant asthma to match the text. Also, why are the FEV1 and the FEV1/FVC lowest in the non-asthmatic coughers in Table 2 ?

RESPONSE: No, the subjects in table 2 were recruited from a specialist cough clinic and are not included in table 1 . We have adjusted the text in table 2 as recommended by this reviewer. Although the absolute $\mathrm{FEV}_{1}$ values are lower in non-asthmatic coughers the \% predicted values are in fact higher. The $\mathrm{FEV}_{1} / \mathrm{FVC}$ ratios are lower in this group although still within normal limits and not likely to be clinical importance

4) Why does Figure $1 \mathrm{~A}$ only have a representative for normal subjects? Is the conclusion that TRPV1 also found in normal subjects? You have data from GPCR that TRPV1 does not differ from normals and asthmatics.

RESPONSE: We undertook the experiments (represented in figure 1) to first establish that we could detect the presence of mRNA for the TRPV family of channels including TRPV1 in human bronchial epithelium. Once this was confirmed we undertook the subsequent sequence of experiments to examine expression of TRPV1 at protein level and its function and potential relevance to the asthmatic airway. We included this in the original manuscript to provide some chronology to our sequence of experiments. However we would be happy to remove this from the revised manuscript if this is felt to be preferable. 
5) What is the significance of the difference of TRPV1 expression by IHC/microarray (i.e., increased with more severe asthma) and then no difference between groups in relationship to function.

RESPONSE: We thank the reviewer for pointing out this interesting observation. The functional findings described in this manuscript (i.e. IL-8 release in response to TRPV1 activation by capsaicin) represent just one consequence of TRPV1 activation. The lack of difference may reflect sample size and we have commented on this issue in our revised marked manuscript (page 14, line 11)

COMMENTS FROM REVIEWER \#2:

The expression of TRPV1, a sensory cation channel was investigated in the airway epithelium of asthmatic patients. Quantitative assessment by immunohistochemistry showed significantly more TRPV1 expression in the epithelium of asthmatics when compared with healthy controls, with the highest expression measured in a group designated as "refractory asthmatics" by the authors. In vitro stimulation of TRPV1 by capsaicin induced IL-8 expression in epithelial cell cultures that was blocked by the antagonist capsazepine. The authors concluded that TRPV1 channels may represent a novel therapeutic target for uncontrolled asthma.

\section{General Comments}

1. While the study investigates an interesting question in regards to the function of TRPV1 on epithelial cells in the airways of asthmatic patients, the relevance of the demonstrated findings remain unclear and the conclusion is over stated. The authors aimed to investigate the effects of environmental irritants on TRPV1, but only capsaicin was used, which is not really an environmental irritant. It would support the claims if the effects of $\mathrm{pH}$ and temperature changes were studied in addition to capsaicin in epithelial cells.

RESPONSE: We thank the reviewer for this very helpful comment. Based on these comments we have undertaken a series of additional experiments on our primary bronchial epithelial cells to evaluate the effect of lowering pH from 7.4 to 6.4 on bronchial epithelial cell membrane currents. We observed large outwardly rectifying currents with typical TRPV1 signature at $\mathrm{pH} 6.4$ which were abrogated with the TRPV1 antagonist capsazepine (see figures 1 and 2 below). This important finding now provides evidence of a physiologically relevant environmental irritant (i.e. acid pH) activating membrane bound TRPV1 channels on bronchial epithelial cells and is very supportive of our original hypothesis. In our revised manuscript we have detailed these additional experiments, described the results and commented on their significance within the discussion 


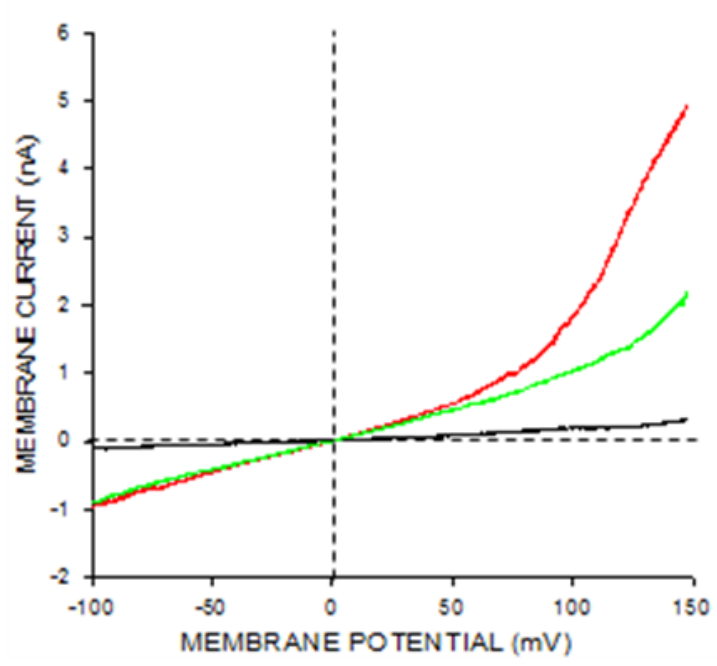

FIGURE 1

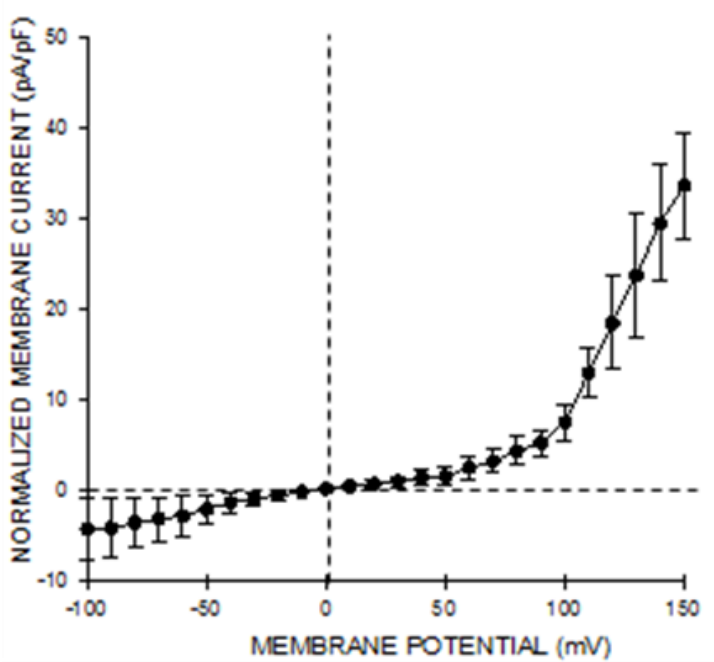

FIGURE 2

2. The rationale and significance of the epithelial cells as opposed to other structural cells of the airways such as fibroblasts and smooth muscle cells is not supported convincingly. In their introduction the authors are creating the impression that coughing and wheezing to environmental irritants maybe due to TRPV expression on the epithelial cells. These responses are in fact directly due to activation of sensory neurons that lead to bronchospasm and coughing/wheezing. This needs to be clarified.

RESPONSE: This is an important point raised by the reviewer. They are correct in pointing out that protective/irritant airway responses such as bronchospasm and cough are directly due to neuronal activation. However there is evidence that neuronal airway responses may be sensitized in disease such as asthma and we propose that activation of TRPV1 on non-neuronal cells (in this case bronchial epithelial cells) by irritants with subsequent release of sensitizing mediators represents one possible mechanism as to how this may arise. We have now revised our introduction to clarify this (see revised marked manuscript page 8 , lines 1-4)

Specific Comments

3. What is the definition of "refractory asthmatics"? This is an important group of patients, and how it was defined needs to be spelled out more clearly.

RESPONSE: As stated in the manuscript '....participants with refractory asthma were recruited from the Belfast City Hospital. All had persisting symptoms despite treatment at Step 4 or 5 of the Global Initiative for Asthma (GINA) guidelines....'. We have now added the following '......fulfilled the ATS definition of refractory asthma (reference - Proceedings of the ATS workshop on refractory asthma. Current understanding, recommendations, and unanswered questions. American Journal of Respiratory and Critical Care Medicine. $2000 ; 162(6): 2341-51)$

4. Was there any statistical correlation between asthma severity and the expression of TRPV1 (either in the mRNA or the protein expression?) RESPONSE: Although epithelial TRPV1 expression in the airway biopsies were significantly greater in asthma compared with health we found no statistical 
correlation between disease severity either defined by lung function, inhaled steroid dose (BDP equivalent) or oral steroid dose.

5. Figure1A: The mRNA bands appear at different levels, what is the explanation for that? Why is there no band at V5? What are the V1-V6 designations?

RESPONSE: We apologise for not clarifying this and have now revised the legend accompanying figure 1 . The V1-V6 designations represent the sub types of the TRPV (vanilloid) family, hence slightly different band levels. TRPV1 was the focus of interest in this manuscript but others (although not TRPV5) appear to be expressed in the samples we studied.

6. Figure 1B: It appears that in lane 2 the $95 \mathrm{kDa}$ band is missing or is very faintly expressed. What is the explanation?

RESPONSE: We believe the differences in band intensity represent differential expression of protein levels between samples.

7. Figure 1C: In the microarray what was the control that the expression level is standardized to? It appears that all of the expression is below 1 .

RESPONSE: The gene expression microarrays were conducted as described previously in J Immunol 2011;186:1861-1869. In brief, two color Agilent whole Human Genome microarrays using a common reference design (utilizing Universal Human Reference RNA, Stratagene, La Jolla, CA for the reference channel) were employed in this study. Gene expression was calculated as the $\log _{2}$ ratio of test and reference channel values. The reference sample facilitates array to array normalization as a technical control. As a result, the expression values ( $\log _{2}$ ratios) for a given gene will be arbitrarily offset based on the relative abundance of mRNA in the Human Reference RNA sample as compared to the test samples.

8. In addition to the epithelium in Figures 2 and 3 there appears to be significant TRPV1 positivity in the submucosal area. This ought to be investigated by the authors, especially in regards to the proinflammatory significance as fibroblasts and smooth muscle cells are a prominent source of IL-8 and similar proinflammatory chemokines.

RESPONSE: This is an important comment from the reviewer. We agree that the role of other non-neuronal cells (e.g. smooth muscle cells) may play a role in TRPV1 mediated inflammatory response. Indeed we have undertaken some preliminary experiments which provides evidence to support this (please see our response below to the reviewers next comment). However we are keen to confine the focus of this current manuscript to the expression and function of TRPV1 in bronchial epithelial cells. We believe our findings in relation to the bronchial epithelium represent an interesting finding. We believe our preliminary experiments in primary smooth muscle cells will form the basis for future work. However if the Editor feels this would improve the manuscript we would be provide this preliminary data.

9. Along the same line, it would be imperative to add experiments in which cultured fibroblast and smooth muscle cells are also investigated for their membrane potential and their expression of IL-8 in response to capsaicin stimulation. 
RESPONSE: We have undertaken some preliminary experiments to confirm that primary human airway smooth muscle cells (ASM) are activated by capsaicin to release IL-8 and this can be almost completely inhibited by the TRPV1 antagonist capsazepine. ASM cells were treated for 24 hours with 10, 25 or 50 $\mu M$ capsaicin or control medium. Supernatants were collected after $24 \mathrm{~h}$ and ELISA was performed to measure the release of IL-8. (see figure 3 below). As indicated in our response above we believe these findings require an extensive programme of work which is outside the focus of our current manuscript.

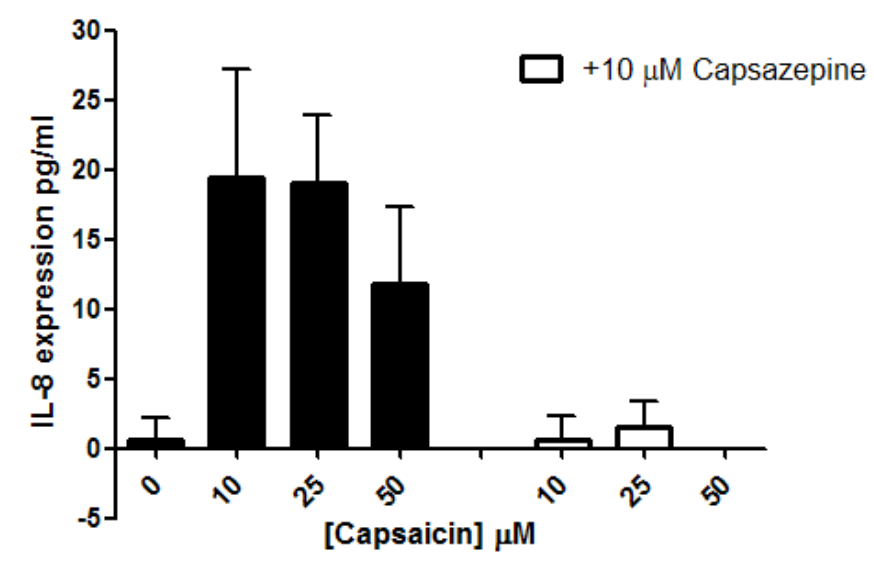

Figure3 Capsaicin induced IL-8 release from primary human airway smooth muscle cells

10. The intracytoplasmic expression of the TRPV1 receptor expression is interesting and needs further experimental support. For example, colocalization with endoplasmic reticulum markers would provide additional support. The functional significance of this TRPV1 as opposed to the membrane expressed molecule needs to be investigated.

RESPONSE: As suggested by the reviewer we have now undertaken some additional immunolabelling experiments demonstrating that TRPV1 does co-localise with ER markers in bronchial epithelial cells (see figure 4 below). We have included this in our results (page 12, line 15-19) and discussion (page 16, line 7-10) section of our revised manuscript. These channels may play a role in ER-Ca2+ release, but to fully establish this would require an extensive programme of work involving the development of routine methods for measuring cytoplasmic and ER Ca2+ in PBECs as well as patch-clamp recording of ER membranes from these cells. Whilst such studies obviously lie beyond the scope and focus of the current work, we believe that our findings do provide an important basis for such studies in the future. 

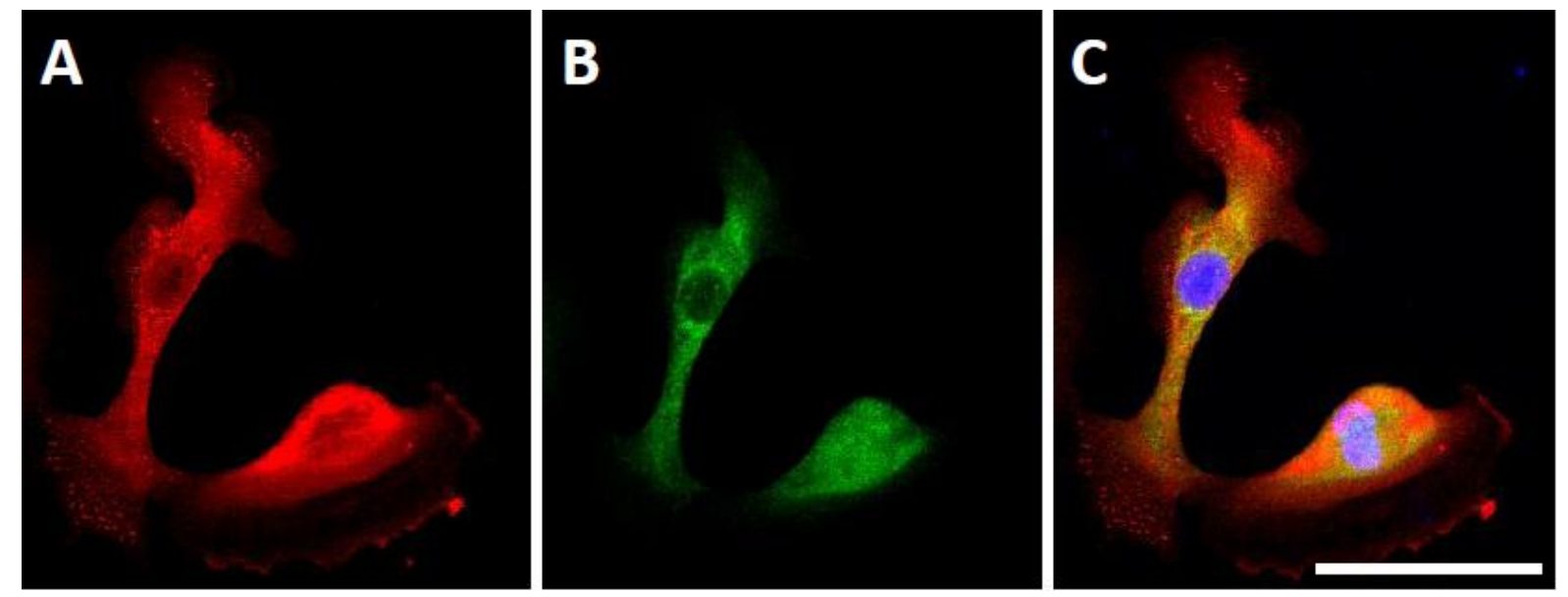

Figure 4: TRPV1 and ER colocalisation in human bronchial epithelial cells. Representative confocal microscopy images (A-C) showing immunohistochemistry staining of bronchial epithelial cells positive for TRPV1 (A) and ER (B) markers. Co-localisation was evident when the images were merged ( $C$; orange/yellow). DAPI stained blue nuclei (C). Scale bar $=100 \mu \mathrm{m}$.

COMMENTS FROM REVIEWER \#3:

This paper presents strong evidence for the presence of the TRPV1 receptor in airway epithelium and suggestive evidence of the increase in its expression in asthma, particularly in severe asthma.

RESPONSE: We are delighted this reviewer believes our paper provides 'strong evidence for the presence of the TRPV1 receptor in airway epithelium'. We have addressed each of their comments below.

\section{My Comments}

1. The subjects with severe asthma were older, had higher IgE levels, and had a greater smoking history than others studied. Do the authors have any data on non-asthmatic smokers to separate this as a potential cause of the increase identified?

RESPONSE: The age and demographic features of the severe refractory group is very typical of this group (Heaney LG et al. Refractory asthma in the UK: cross-sectional findings from a UK multicentre registry. Thorax. 2010 Sep;65(9):787-94). As discussed above, we have also recently published a detailed analysis on smokers, never smokers and ex-smokers with severe asthma and some of the features alluded to by the Reviewer are again typical of this more severe group (Thomson NC et al. Clinical outcomes and inflammatory biomarkers in current smokers and ex-smokers with severe asthma. J Allergy Clin Immunol. $2013 \mathrm{Apr} ; 131(4): 1008-16)$. It is an intriguing possibility that that ex-smoking may potentially contribute to some of the 'steroid resistant' mechanisms, which defines this severe population and we discuss this in our previous manuscript. However, we would argue that whatever the mechanism, the fact that our patients are precisely characterised in this cohort with regard to diagnosis, physiology and adherence with asthma therapy does not alter the significance of the findings.

2. The authors comment that TRPV1 receptors were identified in submucosal cells. To what degree could these cells have contributed to their 
findings of increased numbers of receptors and to increased activity in asthma?

RESPONSE: This is an important point raised by this reviewer. It is likely that a number of other non-neuronal cells in addition to bronchial epithelial cells express functional TRPV1 receptors. In our response to one of the other reviewers (Reviewer \#2) comments above, we have provided some preliminary evidence that this is the case for primary airway smooth muscle cells. However we believe this is outside of the scope of the current manuscript.

3. The authors state that TRPV1 receptors respond to LTB4. It would be of interest to know whether other leukotriene mediators share this property as it would further the link between expression of asthma and the function of these receptors.

RESPONSE: There is no current evidence that other leukotriene mediators (e.g. LTD4 or LTE4) directly activate TRPV1 in the same fashion as LTB4. However it is clear that other products of lipoxygenase (e.g. 15(s)-HETE) are potent TRPV1 agonists and as such represent additional mechanisms whereby inflammatory mediators relevant to asthma may modulate TRPV1 function.

We hope this response and revised manuscript addresses the issues raised during the review process.

With best wishes

Yours Sincerely

Lorcan McGarvey (on behalf of the authors) 
1 channels in severe asthma

3

5

6

7 Heaney, $\mathrm{MD}^{1}$.

8

Corresponding author:

Dr Lorcan McGarvey,

Lisburn Road, Belfast, BT9 7AB

Northern Ireland, UK.

Lorcan P McGarvey, MD, ${ }^{1}$ Claire A Butler, PhD,${ }^{1}$ Susan Stokesberry, PhD, ${ }^{1}$ Liam Polley, MD, ${ }^{1}$

Stephen McQuaid, PhD, ${ }^{2}$ Hani'ah Abdullah, PhD, ${ }^{1}$ Sadaf Ashraf, ${ }^{3}$ Mary K McGahon, ${ }^{3}$ Tim M

Curtis, ${ }^{3}$ Joe Arron MD, PhD, ${ }_{-}^{3}{ }_{-}^{4}$ David Choy, $\mathrm{BSC}^{3}{ }_{-}^{3}-{ }_{-}^{4}$ Tim J Warke, MD, ${ }^{1}$ Peter Bradding, DM, ${ }^{4}-\underline{5}$

Madeleine Ennis, PhD, ${ }^{1}$ Alexander Zholos, PhD, ${ }_{-}^{5}{ }_{-}^{6}$ Richard W Costello, MD, ${ }_{-}^{6}{ }_{-}^{7}$ and Liam G

${ }^{1}$ Centre for Infection and Immunity, Health Sciences Building, Queens University Belfast,

Lisburn Road, Belfast, BT9 7BL $-\mathrm{UK}_{-}^{2}{ }^{2}$ Tissue Pathology, Belfast Health and Social Care Trust,

Belfast, BT9 7AB, UK- ${ }^{3}$ Centre for Vision and Vascular Science, Queen's University Belfast,

Grosvenor Road, Belfast, BT12 6BA, UK ${ }_{t}^{4}$ Genentech, 1 DNA Way, South San Francisco,

Formatted: Superscript

California, USA, ${ }^{4}$ Institute ${ }^{5}$ Institute for Lung Health, Dept or Infection, Immunity and Inflammation, University of Leicester, Leicester, UK ${ }^{5}$ Centre ${ }^{6}$ Centre for Vision and Vascular

Science, Queen's University Belfast, UK and Institute of Biology, Taras Shevchenko Kiev

National University, Kiev 03022, Ukraine, ${ }^{6}$ Department ${ }^{7}$ Department of Respiratory,

Otolaryngology and Molecular Medicine, Education and Research Centre, Smurfit Building,

Royal College of Surgeons in Ireland, Dublin 9, Ireland

Centre for Infection and Immunity, Queens University Belfast. Level 8, Belfast City Hospital, 


\section{Phone: +442890263821 \\ Fax: +442890263879 \\ ABSTRACT (250 words)}

Background: The airway epithelium is exposed to a range of physical and chemical irritants in the environment which are known to trigger asthma. Transient Receptor Potential (TRP) cation channels play a central role in sensory responses to noxious physical and chemical stimuli. Recent genetic evidence suggests an involvement of TRPV1, one member of the vanilloid subfamily of TRP channels, in the pathophysiology of asthma. The functional expression of TRPV1 on airway epithelium has yet to be elucidated.

Objective: In this study we examined the molecular, functional and immunohistochemical expression of TRPV1 in the asthmatic and healthy airway.

Methods: Bronchial biopsies and bronchial brushings were obtained from healthy volunteers $(n=18)$, mild to moderate asthmatics $(n=24)$ and refractory asthmatics $(n=22)$. To investigate the functional role of TRPV1, cultured primary bronchial epithelial cells (PBEC) from mild asthmatics $(n=4)$, non asthmatic coughers $(n=4)$ and healthy subjects $(n=4)$ were studied.

Results: Quantitative immunohistochemistry revealed significantly more TRPV1 expression in asthmatics compared to healthy subjects and with greatest expression in the refractory asthmatics $(p=0.001)$. PCR and Western blotting analysis confirmed gene and protein 

electrophysiology directly confirmed functional TRPV1 expression in all three groups. In

3 functional assays, the TRPV1 agonist capsaicin induced dose dependent interleukin-8 (IL-8)

4

7 Conclusions: Functional TRPV1 channels are present in the human airway epithelium and

8 are over-expressed in the airways of refractory asthmatics. These channels may represent a 9 novel therapeutic target for uncontrolled asthma. 
1

2 TRPV1 is a functional channel activated by physical and chemical irritants. We report its

3 overexpression in asthmatic airway epithelium most notably in severe disease suggesting a

4 role in uncontrolled asthma.

\section{Capsule summary (35 words)}

6 The Transient Receptor Potential vanilloid-1 (TRPV1) channel regulates responses to irritant

7 stimuli. We report TRPV1 overexpression in asthmatic airway epithelium most notably in severe disease suggesting its potential as a therapeutic target for uncontrolled asthma.

Key words: ion channel, sensory, asthma, irritant, chemical, exacerbation, cough

Abbreviations:

TRP - Transient Receptor Potential

TRPV1 - Transient Receptor Potential Vanilloid-1

GINA - Global Initiative for Asthma Guidelines

PBEC - Primary bronchial epithelial cell

qPCR - Quantitative real-time PCR

17

GMA - glycol methacrylate 
During an exacerbation of asthma, the airways become hypersensitive and patients are

3

often troubled with bouts of cough and wheeze following exposure to relatively innocuous stimuli such as aerosols, strong odours or changes in air temperature. The precise mechanism for this airway hypersensitivity is not known but upregulation of receptors responsible for sensing chemical and physical stimuli may be relevant. The recently described Transient Receptor Potential (TRP) proteins, a family of $\mathrm{Ca}^{2+}$ permeable non selective cation channels which sense a vast array of chemical and physical stimuli $(1,2)$, are believed to have an important role in the regulation of airway function in both health and disease $(3,4)$. Recent data has provided genetic evidence for the involvement of one subfamily member, TRP vanilloid 1 (TRPV1) in asthma pathophysiology (5).

TRPV1 is activated by capsaicin (the pungent principle contained in hot chilli peppers) and inhaled capsaicin causes cough (6) and bronchospasm (7) in asthmatics. The airway inflammatory events which accompany an exacerbation of asthma include a rise in airway temperature (8), acidosis (9) and release of mediators derived from lipoxygenase metabolism of arachidonic acid $(4,10)$. TRPV1 is primarily recognised as a heat thermal sensor, but it is also readily activated by low extracellular $\mathrm{pH}(11,12)$ and lipoxygenase products such as leukotriene $B_{4}$. (13). TRPV1 receptors are expressed in several cell types in human airway including sensory neurones (14), smooth muscle cells (15) and epithelial cells from both the upper (16) and lower airway (17). As the bronchial epithelium has an important role in sensing and responding to noxious stimuli we hypothesised that TRPV1 is over expressed in the airway epithelium of asthmatics, in particular those with difficult-to- 
treat asthma. and that Further we considered that the inflammatory response following irritant activation of airway epithelial TRPV1 has a functional role imay contribute to heighted neuronal reflexes responsible for cough and bronchospasm in asthma.A asthmamay pathogenesis and airway responses to environmental irritants.

In this study, we examined both TRPV1 expression and function in human bronchial epithelium. In addition we provide evidence for the overexpression of TRPV1 in the airways of severe asthmatics compared to mild asthmatics and healthy subjects. Some of the results of these studies have been reported in abstract form (18).

\section{METHODS AND MATERIALS}

\section{Full methodological details are provided in an online data repository}

\section{Study Subjects}

Participants with refractory asthma were recruited from the Belfast City Hospital. All had persisting symptoms despite treatment at Step 4 or 5 of the Global Initiative for Asthma (GINA) guidelines. Mild to moderate asthmatics had a clinical diagnosis of asthma with a current history of recurrent wheezing and documented response to asthma medication. Bronchial biopsy samples from this Belfast cohort were analysed using immunohistochemistry (IHC). For examination of in vivo gene expression of TRPV1 in airway epithelium an additional cohort of subjects from Leicester were recruited. Demographic details of both cohorts are shown in Table 1 . To investigate the functional role of TRPV1, primary bronchial epithelial cell (PBEC) cultures were grown from bronchial brushings 
1

obtained from mild asthmatics and non-asthmatic patients recruited from a specialist cough clinic (19) and healthy participants recruited by advertisement. Demographic details are shown in Table 2.

The study was approved by the appropriate Institutional Research Ethics Committees (details in online data repository). Written informed consent was gained from all participants prior to their involvement.

\section{Bronchoscopy and sample processing}

All asthmatic participants were clinically stable at the time of bronchoscopy, and had an $\mathrm{FEV}_{1}>60 \%$ predicted. Bronchial biopsies and brushings were obtained from segmental airways using a standard techniques. Three biopsies from each participant (Belfast Cohort) were submitted for immunohistochemistry studies. Gene expression microarray analysis (and qPCR) was performed on fresh bronchial brushings (Leicester cohort). To investigate the functional role of TRPV1, PBEC cultures from bronchial brushings were cultured as described previously (20). These were obtained from mild asthmatic $(\mathrm{n}=4)$, non asthmatic patients with chronic cough $(n=4)$ and healthy volunteers $(n=4)$.

Immunohistochemistry

Twenty eight biopsies (10 healthy volunteer, 8 mild asthmatic and 10 severe asthmatic biopsies) were processed for immunohistochemistry (IHC) using local protocols as detailed in the online data repository. For TRPV1 and ER co-localisation experiments local protocols were employed as detailed in the online data repository. 
Gene expression analysis

Bronchial brushings and PBEC cultures

Real-time PCR (qRT-PCR) analyses were performed using RNA from bronchial brushings using

TaqMan ${ }^{\circledR}$ Gene Expression Assays (Applied Biosystems, Foster City, CA) as previously described (21). RNA was amplified (Ambion,) for Agilent (Santa Clara, CA) two color Whole Human Genome (WHG) 4x44k gene expression microarray analysis.

PBECs were trypsinised and total RNA extracted using the RNeasy Mini Kit (Qiagen, Hilden, Germany) and qRT-PCR performed using a 7300 Real Time PCR system (Applied Biosystems, Foster City, CA). More information including detail on GAPDH and TRPV1 forward and reverse primers is provided in the online data repository.

\section{Western Blotting}

Protein concentration was determined using BCA protein assay kit (Thermo Scientific, Wilmington, USA) and protein expression determined using a rabbit polyclonal TRPV1 antibody (ab63083; Abcam, Cambridge, UK), at a dilution of 1:3000 followed by incubation for $1 \mathrm{~h}$ with the secondary antibody, HRP-labelled anti-rabbit (1:3000; Bio-Rad Laboratories, Hercules, CA, USA). More details provided in online data repository.

TRPV1 agonists / antagonist experiments in PBECS

Capsaicin is a selective TRPV1 agonist and in this study cultured PBECs were treated with either 10, 25 or $50 \mu \mathrm{M}$ capsaicin or control medium for $24 \mathrm{~h}$ and the concentration of IL-8 measured by ELISA ( $R$ \& D Systems Europe Abingdon, UK). For the antagonist experiments, PBECs were pretreated for 20 min with $10 \mu \mathrm{M}$ of the selective TRPV1 antagonist capsazepine.

Patch clamp experiments 
1

Whole-cell currents were recorded using borosilicate heat-polished patch pipettes (2-3 M $\Omega$ resistance when filled with the pipette solution) and an Axopatch 200B amplifier (Molecular Devices, Union City, CA, USA) interfaced to Digidata 1322A using the pClamp 9 software (Molecular Devices) as previously described by ourselves (22) and detailed in the online data repository.

Data Analysis

Data are presented as means \pm SEM. For statistical analysis a one way ANOVA was performed with Bonferroni test for multiple comparisons. Kendall's tau b statistical analysis was used to examine the trend in biopsy expression by participant group. Patch clamp data were analysed and plotted using Origin 8 (OriginLab, Northampton, MA, USA). A P value $<0.05$ was considered significant.

\section{RESULTS}

\section{Confirmation of TRPV1 expression in cultured human bronchial epithelial cells.}

Gene expression for multiple members of the TRPV family including TRPV1 (but not TRPV5) was identified in PBECs from healthy controls $(n=3)$ (Figure 1A). TRPV1 protein was detected at its expected molecular mass of $95 \mathrm{kDa}$ by Western blotting in the same samples (Figure 1B).

Molecular identification and localisation (immunohistochemical expression) of TRPV1 in healthy and asthmatic epithelium

Microarray 
1

2

Using gene expression microarray analysis of bronchial brush samples from the Leicester cohort we found significantly greater levels of TRPV1 expression (median, IQR) in severe asthmatics $(0.673,0.452-0.761)$ compared to mild/moderate asthmatics $(0.341,0.167-0.538$, $p=0.008)$ and healthy volunteers $(0.322,0.155-0.410, p=0.004)$ (Figure $1 C$ ).

\section{Quantitative $P C R$.}

TRPV1 mRNA was detected in all of the epithelial brush samples. There was no difference in median (IQR) relative fold expression of TRPV1 mRNA calculated as Delta Delta $\mathrm{C}_{\mathrm{T}}$ values between groups: $-1.262(-3.598,2.518),(,-2.523(-4.040,1.362)$ and $-1.289(-4.746,1.624)$ in healthy volunteers, mild / moderate asthmatics and severe asthmatics respectively (see Figure E1 in online data repository)

\section{Immunohistochemistry}

Immunohistochemistry revealed bronchial epithelial expression of TRPV1 in healthy volunteers, mild/moderate asthmatics and severe asthmatics (Figures 2A, B and C, respectively). Dual labelling immunofluoresence confirmed the expression of TRPV1 on cytokeratin positive epithelial cells (Figures 3 A, B and C). We observed an intracytoplasmic distribution of the TRPV1 and to further characterise this we undertook additional experiments demonstrating immunohistochemistry staining of bronchial epithelial cells positive for TRPV1 (Figure 4A) and ER (Figure 4B) markers. Colocalisation was evident when the images were merged (Figure 4C).

We observed There was-greater TRPV1 expression in asthmatic epithelium compared to healthy subjects (Figure 4푸 $p=0.001$ ). 
2 Mean membrane capacitance of PBEC was $30.8 \pm 4.3 \mathrm{pF}(n=6)$. In unstimulated cells, only

3 small background currents could be recorded in the whole range of membrane potentials

4 to capsaicin was significant $(p=0.007)$.

tested, from -100 to $+140 \mathrm{mV}$ (Figure $5 \mathrm{~A} \underline{6 \mathrm{~A}}$, left panel). The I-V relationship of the mean background current normalised by the membrane capacitance to account for some

variations in cell size is shown in Figure $5 \mathrm{~B} \underline{6 \mathrm{~B}}$. It should be noted that composition of the external and pipette solutions was such that this facilitated isolation of cation currents but precluded activation of any potassium or calcium-dependent conductances. Capsaicin application $(50 \mu \mathrm{M})$ caused rapid activation of large outwardly rectifying currents (Figure $5 A \underline{6 \mathrm{~A}}$, middle panel), which is the characteristic "biophysical" signature of TRPV1 channels. This effect was completely reversible upon capsaicin wash-out (Figure 5A6A, right panel). Corresponding I-V relationships are shown in Figure $5 \underline{6 \mathrm{6C}}$. The capsaicin-induced currents reversed close to $0 \mathrm{mV}$ indicating their non-selective cation nature.

To investigate the time course of these responses, voltage ramps over the same range of potentials were applied at $10 \mathrm{~s}$ interval. Figure $6 \mathrm{~A} \underline{7 \mathrm{~A}}$ shows a typical response to $50 \mu \mathrm{M}$ capsaicin application consisting of rapid activation and desensitisation in the continuous presence of the agonist, which developed over 2-3 min. The I-V relationships which were measured in this experiment in control, at the peak response and after agonist wash-out are shown in Figure $6 \mathrm{~B}$ (compare to I-V curves in Fig. $6 \mathrm{C}$ measured by voltage steps), while the mean results are summarised in panel $C$. The increase in current amplitude in response 13 
Reduction of external pH from 7.4 to 6.4 activated inward and outward currents in cells from healthy patients which were partially inhibited by the addition of the selective TRPV1 antagonist capsazepine ( $5 \mu \mathrm{M}$; Fig. 8A). The mean capsazepine-sensitive I-V relation (Fig. 8B

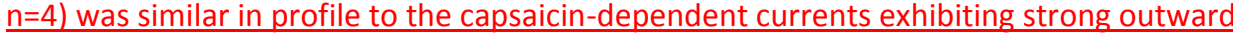
rectification and reversal close to $0 \mathrm{mV}$.

\section{Functional expression of TRPV1 in cultured human primary bronchial epithelial cells}

\section{Dose-dependent induction of IL-8 release from cultured human PBECS by capsaicin}

Dose-dependent induction of IL-8 release by capsaicin was observed within each study group although there was no significant difference in fold increase in IL-8 between asthmatic and non asthmatic groups which may relate to sample size (data not shown). The dose dependent increase in IL-8 release when data from all three groups was therefore pooled has been presented in figure 7A9A. When compared to basal a marginal 1.25 -fold increase in IL-8 release was observed following incubation with $10 \mu \mathrm{M}$ capsaicin with significant increases of 1.76 -fold $(p<0.01)$ and 2.15 -fold $(p<0.001)$ compared to basal observed following incubation with 25 and $50 \mu \mathrm{M}$ doses of capsaicin, respectively.

To further test the specificity of the capsaicin effect, we used selective TRPV1 blocker capsazepine. Capsazepine significantly inhibited capsaicin-induced IL-8 release compared to $25 \mu \mathrm{M}$ capsaicin alone $(\mathrm{p}<0.001)$ and compared to $50 \mu \mathrm{M}$ capsaicin alone $(\mathrm{p}<0.001)$. The data for $n=9$ individual experiments is shown in Figure $7 \mathrm{~B} 9 \mathrm{~B}$. 
3 In this study we have shown for the first time that TRPV1, which is primarily recognised as

4 the major neuronal hot receptor $(23,24)$, is expressed and functional in human bronchial

5 epithelium. In primary bronchial epithelial cell cultures we have shown that pharmacological

6 activation of the TRPV1 channel with capsaicin induces IL-8 release which can be attenuated

7 by pre-treatment with the selective TRPV1 antagonist capsazepine.

Interestingly, TRPV1 expression in the airway was increased in asthmatic subjects compared to healthy controls with a further increase in subjects with refractory asthma. Thus, overexpression may have a role in symptoms associated with irritant exposure in asthma, particularly in patients with persisting symptoms despite treatment with high dose antiinflammatory therapy. Understanding the role of TRPV1 in refractory asthma may therefore identify a novel target for anti-inflammatory therapy in more severe disease.

We believe that bronchial epithelial TRPV1 channels are ideally positioned to detect chemical and physical irritants (e.g. inflammatory mediators, environmental pollutants, acid $\mathrm{pH}$ and changes in temperature) in the airway lumen. To date, most of the focus has been on the role of neuronal TRPV1 in the human airway $(14,25)$. Direct activation of irritant neural receptors mediates reflex responses such as cough and bronchospasm, thus protecting the airway from noxious chemical and physical irritants. However, TRPV1 expression at both an mRNA and protein level-has been reported in a variety of nonneuronal tissues and cell typesand therefore we hypothesised that the airway responses to environmental stimuli might in part be regulated by the bronchial epithelial TRPV1 
1

receptors. Recent studies in immmortalised human-airways epithelial cell lines provide some support for this $(17,26)$ although evidence for this-in human disease is lacking. In this study Here we have providedprovide in vivo and ex vivo evidence of TRPV1 expression and function in human airway biopsies and cultured primary bronchial epithelial cells with specific relevance to refractory asthma.

We observed an intracytoplasmic distribution of the receptor in bronchial epithelial cells

which has been as observed in other cell types $(27,28)$. The intracellular localisation of TRPV1 (in particularOur finding of TRPV1 staining in the endoplasmic reticulumf in the airway epithelium is consistent with its functional role as a $\mathrm{Ca}^{2+}$ store release channel regulating intracellular $\mathrm{Ca}^{2+}$ homeostasis. Robust membrane current responses to the TRPV1 agonist capsaicin (Figs. 5 and 6) suggest strongly that plasmalemmal TRPV1 is also expressed and functional in PBEC, although the precise location and function of bronchialepithelial cell membrane and intracellular TRPV1 requires further study. We also observed TRPV1 staining on a number of submucosal cells although the focus of this present study is confined to the bronchial epithelial expression. Previous studies from chronic coughers (14) and healthy subjects (15) have reported only sparse TRPV1 expression in the airway epithelium, although greater expression has been reported-in the human-upper airway (29). Wesuggest ADifferences in tissue processing, antibodies used and clinical phenotype may explain the discrepancy. Fo-vercome issues regarding specificity of antibodies weln our studies to evaluated the functional properties of TRPV1 on bronchial epithelium. In these experiments we saw that TRPV1 on-PBECs responded to the TRPV1 agonist capsaicin with the release of pro-inflammatory mediators and that thiswhich was blocked by capsazepine, a TRPV1 selective antagonist. We chose to measure-CEapsaicin induced IL-8 release from bronchial 
epithelial cells as this hadhas been previously observed in both human esophageal (30) and human corneal epithelial cells (31) but not before in culturedprimary bronchial epithelial eulturesPBECs. In addition, As IL-8 is known to induce and maintain neural sensitization and activation of nociceptors $(32,33)$ - Therefore, our data provide a mechanistic link whereby activation of activation of bronchial epithelial TRPV1 changes in airway $\mathrm{pH}$ or temperature (during exacerbations) may sensitize airway sensory neurones and contribute to the airway and cough hypersensitivity that characterises asthma through the cross-talk between epithelial and neuronal TRPV1.

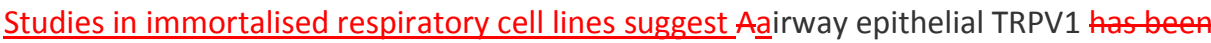
shown toregulates cell apoptosis in response to environmental irritants such as particulate matter and ash(34). These have been confined to immortalised respiratory cell lines whereas our findingshere, we provide the first evidence of a functional airway epithelial TRPV1 channel function in primary cells from the airway. We also provide further evidence of TRPV1 channel function lin our the whole-cell patch clamp experiments on PBECs ourThese-results provided a-direct evidence offor the presence of functional TRPV1 in the plasma membrane that can thus-mediate membrane depolarisation and calcium influx; steps which are necessary for release of pro-inflammatory mediators (35). Both kinetics and voltage-dependent properties of capsaicin-induced currents in PBEC are consistent with TRPV1 biophysical features, such as slow activation/deactivation and strong outward rectification.

Asthmatics commonly report symptoms triggered by a variety of chemical and physical irritants and because-TRP channels have the capacity to sense a vast range of stimuli-and their role in airways disease is currently under intense investigation (1). In our 
1

2

immunohistochemical studies we have shown that TRPV1 is over expressed in the bronchial epithelium of asthmatics compared to healthy subjects and patients with refractory asthma express more epithelial TRPV1 than those with mild/moderate asthma. This was supported by our microarray analysis demonstrating confirming increased expression of TRPV1 genes in the more severe asthmatics. Although on quantitative PCR, mRNA was not concordant with protein abundance, it has become increasingly clear that at the genomic level, mRNA expression does not consistently predict corresponding protein levels $(36,37)$. This may because of complex post-transcriptional and translational modification and /or that different biological mRNA and protein degradation rates may affect correlation. Post translational modification of TRPV1 has been described in experimentally induced tissue injury (38) and

therefore may occur in the inflamed asthmatic airway.

While the vast majority of asthmatics respond to standard doses of current treatments (in particular corticosteroids), a proportion remain symptomatic despite treatment at GINA

Step 4/5 and are considered to have difficult or treatment refractory asthma. Our finding

that bronchial epithelial TRPV1 is over expressed in human bronchialepithelium and upregulatedin refractory (steroid-resistant) asthma suggests that its activation may represent a novel pro-inflammatory pathway. Clinical trials of TRP receptor antagonists in man-have been undertaken in other abnormal hypersensitive states including neuropathic pain and these drugs may prove effective in improving symptom control in asthma as well.

Our findings suggest that the bronchial epithelium may sense and respond to environmental stimuli via TRPV1 activation. However it is not clear how bronchial epithelial cells signal to afferent sensory nerves. We suggest that release of sensitizing mediators such as IL-8 may be one such mechanism. Such mediators may enhance and augment neurogenic 
1 inflammation and nociceptive signalling. Therefore, pharmacological modulation of this

2 receptor may be useful in the treatment of uncontrolled asthma.

\section{ACKNOWLEDGEMENTS}

5 SS was supported by a grant from Northern Ireland Chest Heart \& Stroke and LP was

6 supported by a grant from Higher Education Authority (North South Research Programme).

7 Work in Leicester and Belfast was supported in part by grants from Genentech,Inc., South

8 San Francisco, CA, USA

9 


\section{REFERENCES}

(1) Nilius B. TRP channels in disease. Biochim Biophys Acta 2007;1772:805-812.

(2) Venkatachalam K, Montell C. TRP channels. Annu Rev Biochem 2007;76:387-417.

(3) Bessac BF, Jordt SE. Sensory detection and responses to toxic gases: mechanisms, health effects, and countermeasures. Proc Am Thorac Soc 2010;7:269-277.

(4) Jia Y, Lee LY. Role of TRPV receptors in respiratory diseases. Biochim Biophys Acta 2007;1772:915-927.

(5) Cantero-Recasens G, Gonzalez JR, Fandos C, Duran-Tauleria E, Smit LA, Kauffmann F, et al. Loss of function of transient receptor potential vanilloid 1 (TRPV1) genetic variant is associated with lower risk of active childhood asthma. J Biol Chem 2010;285:27532-27535.

(6) Doherty MJ, Mister R, Pearson MG, Calverley PM. Capsaicin responsiveness and cough in asthma and chronic obstructive pulmonary disease. Thorax 2000;55:643-649.

(7) Hathaway TJ, Higenbottam TW, Morrison JF, Clelland CA, Wallwork J. Effects of inhaled capsaicin in heart-lung transplant patients and asthmatic subjects. Am Rev Respir Dis 1993;148:1233-1237.

(8) Paredi P, Kharitonov SA, Barnes PJ. Faster rise of exhaled breath temperature in asthma: a novel marker of airway inflammation? Am J Respir Crit Care Med 2002;165:181-184.

(9) Hunt JF, Fang K, Malik R, Snyder A, Malhotra N, Platts-Mills TA, et al. Endogenous airway acidification. Implications for asthma pathophysiology. Am J Respir Crit Care Med 2000;161:694-699.

(10) Dahlen SE, Hedqvist P, Hammarstrom S, Samuelsson B. Leukotrienes are potent constrictors of human bronchi. Nature 1980;288:484-486.

(11) Geppetti P, Trevisani M. Activation and sensitisation of the vanilloid receptor: role in gastrointestinal inflammation and function. Br J Pharmacol 2004;141:1313-1320.

(12) Dhaka A, Uzzell V, Dubin AE, Mathur J, Petrus M, Bandell M, et al. TRPV1 Is Activated by Both Acidic and Basic pH. J Neurosci 2009; 29: 153-158.

(13) Hwang SW, Cho H, Kwak J, Lee SY, Kang CJ, Jung J, et al. Direct activation of capsaicin receptors by products of lipoxygenases: endogenous capsaicin-like substances. Proc Natl Acad Sci U S A 2000;97:6155-6160. 
(14) Groneberg DA, Niimi A, Dinh QT, Cosio B, Hew M, Fischer A et al. Increased expression of transient receptor potential vanilloid-1 in airway nerves of chronic cough. Am J Respir Crit Care Med 2004;170:1276-1280.

(15) Mitchell JE, Campbell AP, New NE, Sadofsky LR, Kastelik JA, Mulrennan SA, et al. Expression and characterization of the intracellular vanilloid receptor (TRPV1) in bronchi from patients with chronic cough. Exp Lung Res 2005;31:295-306.

(16) Yamamoto Y, Taniguchi K. Immunolocalization of VR1 and VRL1 in rat larynx. Auton Formatted: French (France) Neurosci 2005;117:62-65.

(17) Agopyan N, Bhatti T, Yu S, Simon SA. Vanilloid receptor activation by 2- and 10-microm particles induces responses leading to apoptosis in human airway epithelial cells. Toxicol Appl Pharmacol 2003;192:21-35.

(18) Butler CA, McQuaid S, Warke T, Stevenson M, Heaney LG, McGarvey L. The Sensory Receptor TRPV1 Is Expressed In Human Bronchial Epithelium And Upregulated In Refractory (Steroid Resistant) Asthma [abstract]. American Journal of Respiratory and Critical Care Medicine : An Official Journal of the American Thoracic Society, Medical Section of the American Lung Association 2010;181:A2490.

(19) McGarvey LP, Heaney LG, Lawson JT, Johnston BT, Scally CM, Ennis M, et al. Evaluation and outcome of patients with chronic non-productive cough using a comprehensive diagnostic protocol. Thorax 1998;53:738-743.

(20) Doherty GM, Christie SN, Skibinski G, Puddicombe SM, Warke TJ, de Courcey F et al. Non-bronchoscopic sampling and culture of bronchial epithelial cells in children. Clin Exp Allergy 2003;33:1221-1225.

(21) Choy DF, Modrek B, Abbas AR, Kummerfeld S, Clark HF, Wu LC et al. Gene expression patterns of Th2 inflammation and intercellular communication in asthmatic airways. $J$ Immunol 2011;186:1861-1869.

(22) Otsuguro Ki, Tang J, Tang Y, Xiao R, Freichel M, Tsvilovskyy V,et al. Isoform-specific inhibition of TRPC4 channel by phosphatidylinositol 4,5-bisphosphate. J Biol Chem 2008; 283: 10026-10036.

(23) Venkatachalam K \& Montell C. TRP Channels. Annual Review of Biochemistry 2007; 76: 387-417.

(24) Vriens J, Appendino G, \& Nilius B. Pharmacology of Vanilloid Transient Receptor Potential Cation Channels. Mol Pharmacol 2009; 75: 1262-1279. 
(25) Watanabe N, Horie S, Spina D, Michael GJ, Page CP, Priestley JV. Immunohistochemical localization of transient receptor potential vanilloid subtype 1 in the trachea of ovalbuminsensitized Guinea pigs. Int Arch Allergy Immunol 2008;146 Suppl 1:28-32.

(26) Veronesi B, Oortgiesen M, Roy J, Carter JD, Simon SA, Gavett SH. Vanilloid (capsaicin) receptors influence inflammatory sensitivity in response to particulate matter. Toxicol Appl Pharmacol 2000;169:66-76.

(27) Lazzeri M, Vannucchi MG, Zardo C, Spinelli M, Beneforti P, Turini D, et al. Immunohistochemical evidence of vanilloid receptor 1 in normal human urinary bladder. Eur Urol 2004;46:792-798.

(28) Olah Z, Karai L, ladarola MJ. Protein kinase C(alpha) is required for vanilloid receptor 1 activation. Evidence for multiple signaling pathways. J Biol Chem 2002;277:35752-35759.

(29) Seki N, Shirasaki H, Kikuchi M, Sakamoto T, Watanabe N, Himi T. Expression and localization of TRPV1 in human nasal mucosa. Rhinology 2006;44:128-134.

(30) Ma J, Altomare A, Guarino M, Cicala M, Rieder F, Fiocchi C, Li D, et al. HCl-induced and ATP-dependent upregulation of TRPV1 receptor expression and cytokine production by human esophageal epithelial cells. Am J Physiol Gastrointest Liver Physiol 2012 1;303(5):G635-45..

(31) Wang Z, Yang Y, Yang H, Capó-Aponte JE, Tachado SD, Wolosin JM, et al. NF-KB feedback control of JNK1 activation modulates TRPV1-induced increases in IL-6 and IL-8 release by human corneal epithelial cells. Mol Vis. 2011;17:3137-46.

(32) Sachs D, Cunha FQ, Poole S, Ferreira SH. Tumour necrosis factor-alpha, interleukin1 beta and interleukin-8 induce persistent mechanical nociceptor hypersensitivity. Pain 2002;96:89-97.

(33) Uçeyler N, Kafke W, Riediger N, He L, Necula G, Toyka KV, et al. Elevated proinflammatory cytokine expression in affected skin in small fiber neuropathy. Neurology. 2010 Jun 1;74(22):1806-13.

(34) Agopyan N, Head J, Yu S, Simon SA. TRPV1 receptors mediate particulate matterinduced apoptosis. Am J Physiol Lung Cell Mol Physiol 2004;286:L563-72.

(35) Karai L, Russell JT, ladarola MJ, Olah Z. Vanilloid receptor 1 regulates multiple calcium compartments and contributes to $\mathrm{Ca} 2+$-induced $\mathrm{Ca} 2+$ release in sensory neurons. J Biol Chem 2004;279:16377-16387.

(36) Guo Y, Xiao P, Lei S, Deng F, Xiao GG, Liu Y, et al. How is mRNA expression predictive for protein expression? A correlation study on human circulating monocytes. Acta Biochim Biophys Sin. 2008;40(5):426-36. 
(37) Chen G, Gharib TG, Huang CC, Taylor JM, Misek DE, Kardia SL, Giordano TJ et al. Discordant protein and mRNA expression in lung adenocarcinomas. Mol Cell Proteomics 2002, 1: 304-313

(38) Szigeti C, Sántha P, Körtvély E, Nyári T, Horváth VJ, Deák É, Dux M, Gulya K, Jancsó G.Disparate changes in the expression of transient receptor potential vanilloid type 1 receptor $m R N A$ and protein in dorsal root ganglion neurons following local capsaicin treatment of the sciatic nerve in the rat. Neuroscience. 2012 Jan 10;201:320-30. 
1 Table 1. Demographic characteristics of the Asthmatic Participants and Healthy Volunteers (Belfast

2 and Leicester cohorts combined). Comparison with the Healthy Volunteer group ${ }^{\dagger} p<0.001,{ }^{\S} p<0.001$,

3 " $p<0.001, * * p<0.001,{ }^{\S \S} p<0.001,{ }^{\ddagger \ddagger} p<0.05,{ }^{\prime \prime \prime \prime} p<0.001$. Comparison with Mild to Moderate

4 Asthmatics: ${ }^{\dagger} p<0.001,{ }^{\ddagger} p=0.007,{ }^{\S} p<0.001,{ }^{\prime} p<0.001,{ }^{* *} p<0.001,{ }^{\dagger \dagger} p<0.0001,{ }^{\S \S} p<0.05,{ }^{* * *} p<0.001$.

\begin{tabular}{|c|c|c|c|c|}
\hline & $\begin{array}{l}\text { Healthy } \\
\text { Volunteers } \\
(n=22)\end{array}$ & $\begin{array}{l}\text { Mild to Moderate } \\
\text { Asthmatics } \\
(n=30)\end{array}$ & $\begin{array}{l}\text { Severe Asthmatics } \\
(n=31)\end{array}$ & p Value* \\
\hline Age (y), median (IQR) & $30(22-45)$ & $29(24-39)$ & $48(38-54)^{+}$ & $<0.0001$ \\
\hline Sex, M/F & $10 / 12$ & $14 / 16$ & $22 / 9$ & 0.09 \\
\hline $\begin{array}{l}\text { Duration of asthma }(y) \text {, } \\
\text { mean } \pm \text { SD }\end{array}$ & $\mathrm{N} / \mathrm{A}$ & $12 \pm 10$ & $22 \pm 15^{\ddagger}$ & 0.007 \\
\hline Atopy, (n) & 11 & 21 & 23 & 0.16 \\
\hline $\mathrm{FEV}_{1}(\mathrm{~L} / \mathrm{min})$, mean $\pm \mathrm{SD}$ & $3.67 \pm 0.78$ & $3.32 \pm 0.77$ & $2.48 \pm 0.67^{\S}$ & $<0.0001$ \\
\hline $\begin{array}{l}\text { FEV }_{1} \text { (\%predicted), mean } \\
\pm \text { SD }\end{array}$ & $102.8 \pm 11.9$ & $93.5 \pm 16.0$ & $75.9 \pm 16.9^{11}$ & $<0.0001$ \\
\hline $\mathrm{FEV}_{1} / \mathrm{FVC}$, mean $\pm \mathrm{SD}$ & $82.1 \pm 9.8$ & $75.9 \pm 10.6$ & $64.6 \pm 11.1^{* *}$ & $<0.0001$ \\
\hline $\begin{array}{l}\text { Inhaled steroid ( } \mathrm{n} \text { ) } \\
\text { BDP equivalent }(\mu \mathrm{g}) \text {, } \\
\text { median (IQR) }\end{array}$ & $\begin{array}{l}0 \\
0\end{array}$ & $\begin{array}{l}19 \\
400(0-800)\end{array}$ & $\begin{array}{l}31 \\
1600(1200-1600)^{++}\end{array}$ & $<0.0001$ \\
\hline $\begin{array}{l}\text { Maintenance systemic } \\
\text { steroids }(n)^{b}\end{array}$ & 0 & 0 & $\begin{array}{l}15 \text { (median dose } \\
\text { prednisolone } 5 \mathrm{mg} \\
{[0-10 \mathrm{mg} \text { ] plus } 1} \\
\text { subject maintenance } \\
\text { intramuscular } \\
\text { triamcinolone) }\end{array}$ & \\
\hline Theophylline, (n) & 0 & 1 & 17 & $<0.0001$ \\
\hline $\begin{array}{l}\text { Long-acting } \beta 2 \text {-agonists, } \\
\text { (n) }\end{array}$ & 0 & 14 & 31 & $<0.0001$ \\
\hline Prior smoking & 1 & 5 & 13 & 0.004 \\
\hline
\end{tabular}




\begin{tabular}{|l|l|l|l|l|}
\hline $\begin{array}{l}\text { history (n) } \\
\text { [pack years, median } \\
\text { range] }\end{array}$ & {$[4]$} & {$[1,1-10]$} & {$[2.5,1-20]$} & \\
\hline $\begin{array}{l}\text { Eosinophils (109/L), } \\
\text { median (IQR) }\end{array}$ & $0.1(0.07-0.21)$ & $0.26(0.14-0.45)^{\ddagger \ddagger}$ & $0.49(0.25-0.74)^{\S \S}$ & $<0.0001$ \\
\hline $\begin{array}{l}\text { IgE (kU/L), geometric } \\
\text { mean (95\% confidence } \\
\text { interval) }\end{array}$ & $24.6(13.3-45.8)$ & $\begin{array}{l}159.8(89.8- \\
284.6)^{\prime \prime I I}\end{array}$ & $\begin{array}{l}238.5(136.2- \\
417.5)^{* * *}\end{array}$ & $<0.0001$ \\
\hline
\end{tabular}

$1 *$ Calculated by ANOVA with Bonferroni's Multiple Comparisons Test (parametric) or Kruskal-Wallis

2 with Dunn's Multiple Comparison Test (non-parametric) or t-test when only asthma groups

3 compared or Chi-squared for categorical variables (sex, atopy, theophylline, long-acting $\beta 2$-agonists, 4 smoking history). 
1 Table 2. Demographic characteristics of the eough variant asthmatiemild asthmatic, non-asthmatic

2 cough and healthy volunteers recruited for experiments on cultured primary bronchial epithelial

3 cells.

\begin{tabular}{|c|c|c|c|c|}
\hline & $\begin{array}{l}\text { Healthy volunteers } \\
(n=4)\end{array}$ & $\begin{array}{l}\text { Cough variantmild } \\
\text { asthmatics } \\
(n=4)\end{array}$ & $\begin{array}{l}\text { Non asthmatic } \\
\text { coughers } \\
(n=4)\end{array}$ & $P$ value \\
\hline $\begin{array}{l}\text { Age, (y) } \\
\text { Median (IQR) }\end{array}$ & $35.5(21.3-43.8)$ & $46.0(39.3-56.8)$ & $58.0(45.0-72.5)$ & 0.05 \\
\hline Sex, M/F & $1 / 3$ & $0 / 4$ & $0 / 4$ & 0.336 \\
\hline $\begin{array}{l}\text { Duration of cough } \\
\text { (m) Mean } \pm S D\end{array}$ & N/A & $49.5(30.0)$ & $57.5(27.0)$ & 0.950 \\
\hline $\begin{array}{l}\text { FEV1 }(\mathrm{L} / \mathrm{min}) \\
\text { Mean } \pm \mathrm{SD}\end{array}$ & $3.45(0.65)$ & $2.52(0.29)$ & $2.3(0.34)^{*}$ & 0.014 \\
\hline $\begin{array}{l}\text { FEV1, \% pred } \\
\text { Mean } \pm \text { SD }\end{array}$ & $107.3(10.59)$ & $105.6(15.23)$ & $118.0(21.28)$ & 0.530 \\
\hline $\begin{array}{l}\text { FEV1/ FVC } \\
\text { Mean } \pm \text { SD }\end{array}$ & $86.6(10.6)$ & $82.73(4.11)$ & $80.2(3.2)$ & 0.446 \\
\hline Atopy (n) & 0 & 0 & 0 & N/A \\
\hline Inhaled steroid (n) & 0 & 4 & 0 & N/A \\
\hline Prior smoking (n) & 0 & 0 & 0 & $\mathrm{~N} / \mathrm{A}$ \\
\hline
\end{tabular}

4

Calculated by ANOVA with Bonferroni's Multiple Comparisons Test (parametric) or Kruskal-Wallis with Dunn's Multiple Comparison Test (non-parametric) or t-test when only cough groups compared or Chi-squared for categorical variables (gender). 
Figure 1: A. Molecular expression of TRPV channels subtypes in human primary bronchial epithelial cells. Conventional RT-PCR showing the expression of TRPV family subtypes including TRPV1 in PBECs from healthy controls $(n=3)$ B. Expression of TRPV1 protein in primary bronchial epithelial-cells (PBECsł. Protein was extracted and analysed by Western blotting (30 $\mathrm{kg}$ protein per sample). Blots were probed using a TRPV1 specific primary antibody (Abcam-63083).TRPV1 specific bands were observed at the molecular weight of 95 KDa in PBECs (lanes 2 to 4, upper panel). TRPV1 transfected HEK cells were used as a positive control (lane 1, upper panel). $\beta$-Tubulin (lower panel) was used to ascertain equal loading (Abcam 6046). Results are representative of two independent experiments. C. Gene expression microarray analysis of bronchial brush samples from healthy, mild/moderate and severe asthmatics. Gene expression microarray analysis was performed on fresh bronchial brush samples from the Leicester cohort comprising severe asthmatics $(n=12)$, mild/moderate asthmatics $(n=16)$ and healthy subjects $(n=8)$. TRPV1 was significantly elevated in severe asthma versus mild moderate asthma (* $p=0.008$ ) and healthy volunteers $(* * p=0.004)$.

Figure 2 - Digital photographic images (A-D) of TRPV1 expression in JB4 sections from (A) moderate asthmatic: the majority of epithelial and submucosal cells express antigen; (C) severe asthmatic: there is -widespread and strong epithelial and submucosal cell 
1

2

3

5

6

7 Bronchial epithelial cells identified by positive red staining with the cytokeratin antibody

8 AE1AE3 (A) were also positive for the TRPV1 (green) (B) and co-localisation was evident

9 when the images were merged (yellow) (C). Representative immunohistochemistry shown

at $\mathrm{X} 400$ magnification

11

expression-of TRPV1. Sections incubated in the absence of antibodies showed no staining; a

representative image is shown in (D). Representative immunohistochemistry shown at X 400 magnification

Figure 3 - Confocal microscopy images $(A-C)$ of double staining immunocytochemistry demonstrating localisation of TRPV1 channels in bronchial epithelium (healthy subject).
Figure 4: TRPV1 and ER colocalisation in human bronchial epithelial cells. Representative confocal microscopy images at X 40 magnification, (A-C) showing immunohistochemistry staining of bronchial epithelial cells positive for TRPV1 (A) and ER (B) markers. Colocalisation was evident when the images were merged (C; orange/yellow). DAPI stained blue nuclei (C). Scale bar $=100 \mu \mathrm{m}$.
Formatted: Font: $12 \mathrm{pt}$

Formatted: Font: 12 pt, Not Bold Formatted: Line spacing: Double Formatted: Font: $12 \mathrm{pt}$ Formatted: Font: $12 \mathrm{pt}$ Formatted: Font: $12 \mathrm{pt}$

Formatted: Font: $12 \mathrm{pt}$ 
1

Figure $\mathbf{5}$. Whole-cell PBEC (healthy subject) membrane current responses to capsaicin application $(50 \mu \mathrm{M})$ measured by voltage-steps. A. Superimposed current traces evoked by 1 s voltage steps before, in the presence of, and after capsaicin wash-out, as indicated. The dotted-Dotted line indicates zero-level current. B. Mean normalised I-V relationship of background current $(n=4)$. C. I-V relationships for the current amplitude measured at the end of each voltage step in the experiment illustrated in panel A.

Figure 6․ Time course of the capsaicin membrane current response. A. Current amplitude was monitored by applying voltage ramps from -100 to $140 \mathrm{mV}$ at $10 \mathrm{~s}$ interval. Circles show current amplitude at $140 \mathrm{mV}$. B. The I-V relationships were derived from the ramps applied before, at the peak response and $3 \mathrm{~min}$ after wash-out of the drug as indicated. C. Mean normalised I-V relationships measured before (squares) and after (circles) capsaicin application $(n=3)$. In each cell, current amplitude at $140 \mathrm{mV}$ in control was normalised as 1.0 .

Figure 8. Whole-cell PBEC (healthy subject) membrane current responses to reduced external pH measured by voltage ramps. A. Superimposed current traces evoked by voltage ramps from -100 to $140 \mathrm{mV}$ at 10 s interval in $\mathrm{pH} 7.4$ and $\mathrm{pH} 6.4$ ( \pm capsazepine; $5 \mu \mathrm{M}$ ) $\underline{\text { external solutions as indicated. The dotted line indicates zero-level current. B. Mean } \pm \text { SEM }}$ I-V relationship (normalized for cell capacitance) of capsazepine-sensitive current ( $=4$ ).

Figure 79. Capsaicin induces IL-8 release from human PBECs (asthmatic and non-asthmatic subjects). PBECs were-treated_ffor24 hours) with 10, 25 or $50 \mu \mathrm{M}$ capsaicin or control medium. Supernatants were collected after $24 \mathrm{~h}$ and EUSA was performed to measure the release of $1 \mathrm{~L}-8$. Values are expressed as the mean release over basal \pm SEM. A. Capsaicin- 
1

2 3 inhibits capsaicin induced IL-8 release from human PBECs. PBECs were pre-treated for 20

4

7 mean release over basal \pm SEM. Capsazepine significantly inhibited capsaicin-induced IL-8

induced IL-8 release ${ }^{* * *} \mathrm{p}<0.001$ compared to control $\mathrm{i}_{\bar{j}}$ casured using a-Kruskal-Wallis test with Dunn's multiple comparison test for $(n=12$ individual experiments). B. Capsazepine min with $10 \mu \mathrm{M}$ capsazepine- Following which media was replacedthen with 10, 25 or $50 \mu \mathrm{M}$ capsaicin or control medium with or without capsazepine. Supernatants were collected after $24 \mathrm{~h}$ and ELISA was performed to measure the release of $1 \mathrm{~L}-8$. Values are expressed as the release $*_{p}^{*}<0.001$ compared to $25 \mu \mathrm{M}\left({ }^{*} \mathrm{p}<0.001\right)$ and Eapsaicin alone and $\underline{50 \mu M}$ $\left(*^{*} \mathrm{p}<0.001\right)$ eompared to $50 \mu \mathrm{MA}$-capsaicin alone;-measured using one way ANOVA with Bonferroni's multiple comparison test for $(n=9$ individual experiments). 


\section{ONLINE DATA REPOSITORY}

\section{Increased expression of bronchial epithelial transient receptor potential vanilloid 1 channels in severe asthma}

Lorcan P McGarvey ${ }^{1}$, Claire A Butler ${ }^{1}$, Susan Stokesberry ${ }^{1}$, Liam Polley ${ }^{1}$, Stephen McQuaid ${ }^{2}$, Hani'ah Abdullah ${ }^{1}$, Sadaf Ashraf ${ }^{3}$, Mary K McGahon ${ }^{3}$, Tim M Curtis ${ }^{3}$, Joe Arron ${ }^{3}$ Arron $^{4}$, David Choy $^{3} \underline{\text { Choy }^{4}}$, Tim J Warke ${ }^{1}$, Peter Bradding ${ }^{4}$-Bradding ${ }^{5}$, Madeleine Ennis ${ }^{1}$, Alexander Zholos ${ }^{5}$ Zholos ${ }^{6}$, Richard Costello ${ }^{6}-$ Costello $^{7}$ and Liam G Heaney ${ }^{1}$.

${ }^{1}$ Centre for Infection and immunity, Health Sciences Building, Queens University Belfast, Lisburn Road, Belfast, BT9 7BL. UK. ${ }^{2}$ Tissue Pathology, Belfast Health and Social Care Trust, Belfast, BT9 7AB, UK.Centre for Vision and Vascular Science, Queens University Belfast, ${ }^{3}$ Genentech ${ }^{4}$ Genentech, 1 DNA Way, South San Francisco, California, USA, ${ }^{4}$ Institute ${ }^{5}$ Institute for Lung Health, Dept or Infection, Immunity and Inflammation, University of Leicester, Leicester, UK ${ }^{5}$ Centre ${ }^{6}$ Centre for Vision and Vascular Science, Queen's University Belfast, UK and Institute of Biology, Taras Shevchenko Kiev National University, Kiev 03022, Ukraine, ${ }^{6}$ Department ${ }^{7}$ Department of Respiratory, Otolaryngology and Molecular Medicine, Education and Research Centre, Smurfit Building, Royal College of Surgeons in Ireland, Dublin 9, Ireland

Corresponding author: Dr Lorcan McGarvey,

Centre for Infection and Immunity, Queens University Belfast. Level 8, Belfast City Hospital,

Lisburn Road, Belfast, BT9 7AB

Northern Ireland, UK.

Formatted: Font color: Auto, English (U.K.)
Formatted: Superscript

Formatted: Superscript

Formatted: Superscript 
Email: I.mcgarvey@qub.ac.uk

Phone: +442890263821

Fax: +442890263879

\section{Study Subjects}

The studies were approved by the Research Ethics Committee of both Institutions (Belfast Office of Research and Ethics Committee of Northern Ireland reference 06/NIR02/114 and 09/NIR02/51, Leicester - Leicestershire, Northamptonshire, \& Rutland Research Ethics Committee reference 04/Q2502/74). Written informed consent was gained from all participants prior to their involvement.

Bronchial biopsies:

Belfast Cohort: Participants with refractory asthma were recruited from the Belfast City Hospital where systematic evaluation protocols ensure patients have well-characterised refractory asthma. All participants had persisting symptoms despite treatment at Step 4 or 5 of the GINA guidelines Global Initiative for Asthma (GINA) (E1). Mild to moderate asthmatic and normal participants were recruited by advertisement and had a clinical diagnosis of asthma with a current history of recurrent wheezing and response to asthma medication. Healthy volunteers had no history of asthma or persistent respiratory symptoms and normal lung function. All asthmatic participants were clinically stable on their usual medication at the time of bronchoscopy, and all participants had an FEV1 of greater than $60 \%$ predicted. Demographic details are shown in Table 1 of the main paper.

Leicester cohort: For the gene expression studies, asthmatic subjects $(n=36)$ and healthy volunteers ( $n=12$ ) were recruited from respiratory clinics including the Leicester Difficult Asthma Clinic, from staff at Glenfield Hospital, and from the general population through 
advertisement (Leicester cohort). Subjects with asthma gave a suggestive history and had objective evidence of variable airflow obstruction as indicated by one or more of the following: (1) methacholine airway hyperresponsiveness ( $\left.\mathrm{PC}_{20} \mathrm{FEV}_{1}<8 \mathrm{mg} / \mathrm{mL}\right),(2)>15 \%$ improvement in $\mathrm{FEV}_{1} 10$ minutes after $200 \mu \mathrm{g}$ inhaled salbutamol, (3) peak expiratory flow ( $>20 \%$ maximum within-day amplitude from twice-daily peak expiratory flow measurements over a period of 14 days). Subjects underwent spirometry; allergen skin prick tests for Dermatophagoides pteronyssinus, dog, cat, grass pollen and Aspergillus fumigatus; a methacholine inhalation test using the tidal breathing method; and sputum induction using incremental concentrations of nebulized hypertonic saline (i.e., $3 \%, 4 \%$, and $5 \%$, each for 5 $\min )(E 2)$. Subjects with asthma also kept a diary card for 2 weeks prior to bronchoscopy, recording daytime and night-time symptoms, daily short-acting $\beta_{2}$-agonist use and twice daily peak expiratory flow (PEF). Asthma severity was defined by British Guideline on the Management of Asthma treatment steps ( mild = step 1, $\beta_{2}$-agonist only; moderate $=$ steps 2 and 3 , inhaled corticosteroid $\leq 800 \mathrm{mg}$ beclomethasone equivalent per day \pm long-acting $\beta_{2^{-}}$ agonist; severe = step 4 and 5) (E3). Of the 16 severe patients at step 4/5, 13 met the American Thoracic Society criteria for refractory asthma (E4).

In both cohorts, all participants were current non-smokers with no upper or lower respiratory tract infection in the 6 weeks prior to their bronchoscopy. All asthmatic participants were clinically stable on their usual medication at the time of bronchoscopy. Demographic details for each cohort are shown in Table 1 in the main manuscript. 
Primary bronchial epithelial cell (PBEC) cultures: To investigate the functional role of TRPV1 we performed a series of experiments on primary bronchial epithelial cell (PBEC) cultures from bronchial brushings obtained from mild asthmatic $(n=4)$ and non asthmatic patients with chronic cough $(n=4)$ referred to the Belfast City Hospital specialist cough clinic (E5). Healthy volunteers $(n=4)$ were recruited by local advertisement. Demographic details for this cohort are shown in Table 2 in the main manuscript.

\section{Bronchoscopy and samples}

Bronchoscopy was performed using a standard technique. In brief, after intravenous sedation and local anaesthesia with topical lignocaine, bronchial biopsies and bronchial brushings were obtained from lobar / segmental airways. One biopsy from each participant was immediately placed in RNA preservative (RNAlater, Ambion, Austin, TX) and submitted for microarray analysis and $\mathrm{qPCR}$ and 3 biopsies placed immediately into dry acetone containing protease inhibitors (iodoacetamide and PMSF) and fixed overnight at $-20^{\circ} \mathrm{C}$. Brushings were placed in RNAlater or Promocell ${ }^{\mathrm{TM}}$ medium containing penicillin/streptomycin and Primocin ${ }^{\mathrm{TM}}$ for cell culture (Promocell UK). PBECs were cultured using methods developed in our laboratory which resulted in homogenous cultures of basal epithelial cells (E6).

For immunohistochemistry (IHC), biopsy samples were processed using local protocols. Twenty eight biopsies (10 healthy volunteer, 8 mild asthmatic and 10 severe asthmatic biopsies) were available for immunohistochemistry. Infiltration and embedding with JB4 resin was performed as previously described (E7). Two $\mu \mathrm{m}$ sections were cut from each biopsy. Endogenous peroxidise was blocked with $0.3 \%$ hydrogen peroxide. All sections were pressure cooked in 0.01M Tris-EDTA pH9.0 on full steam for 3 minutes for antigen retrieval. 
Sections were incubated with TRPV1 polyclonal antibody (1:200, Abcam), overnight at $4^{\circ} \mathrm{C}$, then primary antibodies were detected by incubation for $30 \mathrm{~min}$ at RT in peroxidase-labelled EnVision anti-rabbit secondary antibody (Dako, Ely, UK) using 3,3'-diaminobenzidine (DAB; Dako, Ely, UK) as chromagen. On selected tissue sections from this series, immunofluorescence was carried out to permit high resolution analysis of TRPV1 antigen distribution. Sections were treated as for IHC and following incubation in a mix of TRPV1 and a monoclonal antibody to the epithelial specific antibody AE1AE3 (1:50, Dako). Antigen binding sites were detected with a mixture of anti-mouse Alexa 568 and anti-rabbit Alexa 488 (Invitrogen). Sections were counterstained with DAPI hardset mounting medium (Vector). All fluorescently stained slides were assessed and digital fluorescent images acquired with a Leica DFC350 FX digital camera and processed using Leica FW4000 software. Immunostained sections were evaluated by two independent persons, following which results were discussed and consensus scoring applied to any conflicting results. A 4-point scoring system was used: 0 - no detectable expression in epithelium or submucosa; 1 - patchy or focal areas of low intensity epithelial expression, not all cells expressing positivity for protein, scattered positivity in submucosa; 2 - moderate / majority of epithelial and submucosal cell expression; 3 - widespread and strong epithelial and submucosal cell expression.

TRPV1 and ER colocalisation in human bronchial epithelial cells.

Human bronchial epithelial cells were grown on coverslips and fixed in $4 \%$

paraformaldehyde (PFA) for 30 minutes at RT. Cells were briefly washed in Phosphate

Buffered Saline (PBS) before being permeabilised with $0.1 \%$ Triton X-100 in PBS for 20

minutes at RT. Cells were blocked with 10\% Bovine Serum Albumin (BSA) in PBS for 1 hour at

Formatted: Font: $12 \mathrm{pt}$ Formatted: Line spacing: Double 
$\underline{\mathrm{RT} \text { and incubated with primary antibodies, mouse monoclonal anti-KDEL (1:500), ER marker }}$ and rabbit polyclonal anti-VR1 (1:200), TRPV1 marker (AB12223 and Ab63083 respectively; Abcam, Cambridge, UK) overnight at $4^{\circ} \mathrm{C}$, followed by incubation for 1 hour at RT with secondary antibodies, Alexa Fluor goat anti-mouse 488 (1:500; Invitrogen) and Alexa Fluor goat anti-rabbit 568 (1:500; Invitrogen). Cell nuclei were stained using Vectashield mounting medium containing DAPI (Vector Labs, Peterborough, UK). Staining was visualised and images captured using Nikon EZ-C1 confocal system running C1 acquisition software (Nikon UK Ltd. Surrey, UK) at x40 magnification.

\section{Gene expression analyses}

RNA was isolated from homogenized bronchial biopsies and real-time PCR (qPCR) was performed as described previously (E8). TaqMan $^{\circledR}$ Gene Expression Assays (Applied Biosystems, Foster City, CA) were purchased and conducted per manufacturer's instructions for TRPV1. RNA was amplified (Ambion,) for Agilent (Santa Clara, CA) two color Whole Human Genome (WHG) 4x44k gene expression microarray analysis. Universal Human Reference RNA (Stratagene, La Jolla, CA) was used for the reference channel. Probe intensities were transformed as $\log _{2}$ ratios of test and reference channels calculated by the Agilent Feature Extraction software, protocol GE2-v5_95 (Agilent). Flagged outliers were not included in any subsequent analyses. All gene expression analyses and plotting were performed using the R Project software package, version 2.10 .1 (refer to http://www.Rproject.org). 


\section{Quantitative Real-Time PCR}

\section{Bronchial brushings}

Real-time PCR (qRT-PCR) analyses were performed using RNA from homogenized bronchial brushings ( 36 subjects; 10 HV, 16 MA and 15 SA) using TaqMan ${ }^{\circledR}$ Gene Expression Assays (Applied Biosystems, Foster City, CA) as previously described. The delta-delta Ct method was used to calculate relative fold expression with GAPDH as housekeeping gene

\section{PBEC cultures}

PBECs were trypsinised and cells lysed using Qiagen RLT buffer (Qiagen, Hilden, Germany) before homogenisation using QIAshredders (Qiagen, Hilden, Germany). RNA was then extracted using the RNeasy Mini Kit (Qiagen, Hilden, Germany). RNA concentration was measured with the nanodrop spectrophotometer (Thermo Scientific, Wilmington, USA) and $1 \mu \mathrm{g}$ RNA was used to synthesise cDNA using the high capacity cDNA reverse transcription kit (Applied Biosystems, Foster City, CA). PBEC cDNA was mixed with Power Sybr Green PCR master mix (Applied Biosystems, Foster City, CA) and either GAPDH or TRPV1 forward and reverse primers (Table E1). The following PCRs were performed in a 7300 Real Time PCR system (Applied Biosystems, Foster City, CA). Melting curves showed formation of only one gene product per primer pair. Normalisations and calibrations of the data from all studies were performed with the $\underline{2^{-\Delta \Delta C}} \underline{I}$ method as described in Applied Biosystems User Bulletin No. $2\left(\mathrm{P} / \mathrm{N}\right.$ 4303859) (27). Delta $\mathrm{C}_{\mathrm{T}}$ was calculated as target gene expression $\left(\mathrm{C}_{\mathrm{T}}\right)$ minus internal housekeeping control, GAPDH gene expression $\left(C_{T}\right)$. Human Universal Reference RNA (Clontech, P/N 639654) was prepared as CDNA and utilised as plate calibrators. DeltaDelta $\mathrm{C}_{\mathrm{T}}$ was calculated as sample Delta $\mathrm{C}_{\mathrm{T}}$ minus plate calibrator Delta $\mathrm{C}_{\mathrm{T}}$. GAPDH and TRPV1 forward and reverse primers are detailed in table E1 below. 
Table E1. Forward and reverse primers for TRPV1 and GAPDH

\begin{tabular}{|l|l|l|l|}
\hline \multicolumn{1}{|c|}{ Primer name } & \multicolumn{1}{|c|}{ Forward } & Reverse & Size (bp) \\
\hline TRPV1 & GCCTGGAGCTGTTCAAGTTC & GCCTGAAACTCTGCTTGACC & 452 \\
\hline TRPV2 & CCAGCTCTCCAGTTTTCAGG & GTTCAGCACAGCCTTCATCA & 365 \\
\hline TRPV3 & TTCCTCATGCACAAGCTGAC & TGCGCTTCACAAAGTCATTC & 490 \\
\hline TRPV4 & CCCGTGAGAACACCAAGTTT & GAAGAGCGTAATGACCTCGC & 374 \\
\hline TRPV5 & TTGCTCAGTTGCTGTCATCC & GCTCCTCTTTGTCGAACGTC & 307 \\
\hline TRPV6 & TCACTTCGCTTCCTGGAACT & ACACGCTTTCCACAAGCTCT & 401 \\
\hline GAPDH & GCTCTCTGCTCCTCCTGTTC & AAATCCGTTGACTCCGACC & 100 \\
\hline
\end{tabular}

Source: Invitrogen

\section{Western Blotting}

PBECs were collected and snap frozen, homogenised and lysed in RIPA buffer supplemented with protease inhibitor cocktail (Roche Diagnostics, Mannheim, Germany). Protein concentration was determined using BCA protein assay kit (Thermo Scientific, Wilmington, USA). $30 \mu \mathrm{g}$ of total protein was separated on the $8 \%$ SDS-Polyacrylamide gel by electrophoresis and transferred to Hybond-P PVDF membrane (GE Healthcare Life Sciences, Buckinghamshire, UK). The membrane was blocked for $30 \mathrm{~min}$ in $3 \% \mathrm{BSA} / \mathrm{PBS}$ and then probed overnight in 3\% BSA/PBS with a rabbit polyclonal TRPV1 antibody (ab63083; Abcam, Cambridge, UK), at a dilution of 1:3000. Followed by incubation for $1 \mathrm{~h}$ with the secondary antibody, HRP-labelled anti-rabbit (1:3000; Bio-Rad Laboratories, Hercules, CA, USA). Images 
were obtained using UVP bioimager (UVP, Cambridge, UK). Benchmark Pre-stained protein standards (Invitrogen, Paisley, UK) were used to determine molecular mass.

\section{Patch clamp experiments}

Whole-cell currents were recorded using borosilicate heat-polished patch pipettes (2-3 M $\Omega$ resistance when filled with the pipette solution) and an Axopatch 200B amplifier (Molecular Devices, Union City, CA, USA) interfaced to Digidata 1322A using the pClamp 9 software (Molecular Devices). Series resistance was compensated by about $70 \%$. Holding potential was $-40 \mathrm{mV}$. Steady-state current-voltage (I-V) relationships were measured by applying either voltage steps (test potentials from -100 to $+140 \mathrm{mV}$ with a $20 \mathrm{mV}$ increment) or slow voltage ramps from -100 to $+140 \mathrm{mV}$. To monitor the time course of TRPV1 activation by capsaicin, the voltage ramps were applied at $10 \mathrm{~s}$ interval. The I-V curves obtained by the voltage ramp and step protocols were similar confirming steady-state channel activity at each test potential when ramps were used.

For experiments involving the addition of capsaicin the The external solution contained (mM): $\mathrm{NaCl}$ 120, glucose 12, HEPES 10, pH 7.4 (adjusted with $\mathrm{NaOH}$ ). Pipette solution contained (mM): CsCl 80, MgATP 1, creatine 5, GTP 1, D-glucose 5, HEPES 10, BAPTA 10, $\mathrm{CaCl}_{2} 4.6\left(\left[\mathrm{Ca}^{2+}\right]_{i}=100 \mathrm{nM}\right), \mathrm{pH} 7.4$ (adjusted with $\left.\mathrm{CsOH}\right)$. For experiments involving altered $\mathrm{pH}$ the external solution contained (mM): $\mathrm{NaCl} 150, \mathrm{CsCl} 6, \mathrm{MgCl}_{2} 1.3, \mathrm{CaCl}_{2} 2$ 2, Glucose, 5; HEPES, 10; pH7.4 or 6.4 with Tris. Pipette solution contained (mM): $\mathrm{CsOH} 130$, D Gluconic Acid $120, \mathrm{MgCl}_{2} \underline{1}$, EGTA $0.5\left(\left[\mathrm{Ca}^{2+}\right]_{i}=30 \mathrm{nM}\right), \mathrm{pH} 7.2$ with Tris. 
IL-8 concentrations were measured from aliquots of culture medium taken $24 \mathrm{~h}$ following treatment with capsaicin (Enzo Life Sciences, Exeter, UK) using a commercial ELISA kit from R \& D Systems Europe (Abingdon, UK).

Data Analysis

Data are presented as means \pm SEM. For statistical analysis a one way ANOVA was performed with Bonferroni test for multiple comparisons. Kendall's tau b statistical analysis was used to examine the trend in biopsy expression by participant group. Patch clamp data were analysed and plotted using Origin 8 (OriginLab, Northampton, MA, USA). A P value < 0.05 was considered significant.

\section{RESULTS}

Real time PCR (qRT PCR) analysis of fresh bronchial brush samples from the Leicester cohort comprising healthy, mild/moderate and severe asthmatics. Analysis was performed on fresh bronchial brush samples from the Leicester cohort comprising severe asthmatics $(n=15)$, mild/moderate asthmatics $(n=16)$ and healthy subjects $(n=10)$. TRPV1 mRNA was detected in all of the epithelial brush samples. There was no difference in median (IQR) relative fold expression of TRPV1 mRNA calculated as Delta Delta $C_{T}$ values between groups: $-1.262(-3.598,2.518),(,-2.523(-4.040,1.362)$ and $-1.289(-4.746,1.624)$ in healthy volunteers, mild / moderate asthmatics and severe asthmatics respectively (see figure E1 below). 


\section{Online Figure Legend}

Figure E1: Real time PCR (qRT PCR) expression of TRPV1 in fresh bronchial epithelial brush samples from healthy volunteers, mild/moderate asthmatics and severe asthmatics.

Analysis of fresh bronchial brush samples from the Leicester cohort comprising healthy $(n=10)$, mild/moderate $(n=16)$ and severe asthmatics $(n=15)$. Data presented as median (IQR) relative fold expression of TRPV1 mRNA calculated as delta delta $\mathrm{C}_{\mathrm{T}}$ values.

\section{References}

E1. Global Strategy for Asthma Management and Prevention GINA Executive Summary. Eur Respir J. 2008;31:1-36. 
E2. Brightling CE, Ward R, Woltmann G, Bradding P, Sheller JR, Dworski R et al. Induced sputum inflammatory mediator concentrations in eosinophilic bronchitis and asthma. Am J Respir Crit Care Med 2000; 162:878-82.

E3. British Guideline on the Management of Asthma. Thorax 2008; 63:iv1-iv121.

E4. Proceedings of the ATS workshop on refractory asthma . Current understanding, recommendations, and unanswered questions. Am J Respir Crit Care Med 2000; 162:2341-51.

E5. McGarvey L, Heaney LG, Lawson JT, Johnston BT, Scally CM, Ennis M, Shepherd DR, MacMahon J Evaluation and outcome of patients with chronic non-productive cough using a comprehensive diagnostic protocol. Thorax 1998;53:738-743.

E6. Doherty GM, Christie SN, Skibinski G, Puddicombe SM, Warke TJ, de Courcey F, Cross AL, Lyons JD, Ennis M, Shields MD, Heaney LG. Non-bronchoscopic sampling and culture of epithelial cells in children. Clin Exp Allergy. 2003 Sep;33(9):1221-5

E7. Britten KM, Howarth PH, Roche WR. Immunohistochemistry on resin sections: a comparison of resin embedding techniques for small mucosal biopsies. Biotech Histochem. 1993;68(5):27180 .

E8. Choy DF, Modrek B, Abbas AR, Kummerfeld S, Clark HF, Wu LC et al. Gene Expression Patterns of Th2 Inflammation and Intercellular Communication in Asthmatic Airways. J Immunol 2010;doi:10.4049/jimmunol.1002568. 
1 Increased expression of bronchial epithelial transient receptor potential vanilloid 1

2 channels in severe asthma

3 Lorcan P McGarvey, MD, ${ }^{1}$ Claire A Butler, PhD, ${ }^{1}$ Susan Stokesberry, PhD, ${ }^{1}$ Liam Polley, MD, ${ }^{1}$

4 Stephen McQuaid, PhD, ${ }^{2}$ Hani'ah Abdullah, $\mathrm{PhD},{ }^{1}$ Sadaf Ashraf, ${ }^{3}$ Mary K McGahon, ${ }^{3}$ Tim M

5 Curtis, ${ }^{3}$ Joe Arron MD, PhD, ${ }^{4}$ David Choy, BSc, ${ }^{4}$ Tim J Warke, MD, ${ }^{1}$ Peter Bradding, DM, ${ }^{5}$

6 Madeleine Ennis, $\mathrm{PhD},{ }^{1}$ Alexander Zholos, PhD, ${ }^{6}$ Richard W Costello, MD, ${ }^{7}$ and Liam G

7 Heaney, $\mathrm{MD}^{1}$.

$8{ }^{1}$ Centre for Infection and Immunity, Health Sciences Building, Queens University Belfast,

9 Lisburn Road, Belfast, BT9 7BL, UK ${ }^{2}$ Tissue Pathology, Belfast Health and Social Care Trust,

10 Belfast, BT9 7AB, UK ${ }^{3}$ Centre for Vision and Vascular Science, Queen's University Belfast,

11 Grosvenor Road, Belfast, BT12 6BA, UK ${ }^{4}$ Genentech, 1 DNA Way, South San Francisco,

12 California, USA, ${ }^{5}$ Institute for Lung Health, Dept or Infection, Immunity and Inflammation,

University of Leicester, Leicester, UK ${ }^{6}$ Centre for Vision and Vascular Science, Queen's

University Belfast, UK and Institute of Biology, Taras Shevchenko Kiev National University,

Kiev 03022, Ukraine, 'Department of Respiratory, Otolaryngology and Molecular Medicine,

Education and Research Centre, Smurfit Building, Royal College of Surgeons in Ireland,

Dublin 9, Ireland

Corresponding author:

Dr Lorcan McGarvey,

Centre for Infection and Immunity, Queens University Belfast. Level 8, Belfast City Hospital, Lisburn Road, Belfast, BT9 7AB

Northern Ireland, UK. 
1 Email: l.mcgarvey@qub.ac.uk ; Phone: +44 2890263821 Fax: +44 2890263879

2

3

4

\section{ABSTRACT (250 words)}

Background: The airway epithelium is exposed to a range of physical and chemical irritants in the environment which are known to trigger asthma. Transient Receptor Potential (TRP) cation channels play a central role in sensory responses to noxious physical and chemical stimuli. Recent genetic evidence suggests an involvement of TRPV1, one member of the vanilloid subfamily of TRP channels, in the pathophysiology of asthma. The functional expression of TRPV1 on airway epithelium has yet to be elucidated.

Objective: In this study we examined the molecular, functional and immunohistochemical expression of TRPV1 in the asthmatic and healthy airway.

Methods: Bronchial biopsies and bronchial brushings were obtained from healthy volunteers $(n=18)$, mild to moderate asthmatics $(n=24)$ and refractory asthmatics $(n=22)$. To investigate the functional role of TRPV1, cultured primary bronchial epithelial cells (PBEC) from mild asthmatics $(n=4)$, non asthmatic coughers $(n=4)$ and healthy subjects $(n=4)$ were studied.

Results: Quantitative immunohistochemistry revealed significantly more TRPV1 expression in asthmatics compared to healthy subjects and with greatest expression in the refractory asthmatics $(p=0.001)$. PCR and Western blotting analysis confirmed gene and protein expression of TRPV1 in cultured primary bronchial epithelial cells (PBEC). Patch-clamp electrophysiology directly confirmed functional TRPV1 expression in all three groups. In 
1 functional assays, the TRPV1 agonist capsaicin induced dose dependent interleukin-8 (IL-8)

2 release which could be blocked by the antagonist capsazepine. Reduction of external pH

3 from 7.4 to 6.4 activated a capsazepine-sensitive outwardly-recifiying membrane current.

4

5 Conclusions: Functional TRPV1 channels are present in the human airway epithelium and

6 are over-expressed in the airways of refractory asthmatics. These channels may represent a

7 novel therapeutic target for uncontrolled asthma.

8 


\section{Clinical Implications (30 words)}

2 TRPV1 is a functional channel activated by physical and chemical irritants. We report its

3 overexpression in asthmatic airway epithelium most notably in severe disease suggesting a

4 role in uncontrolled asthma.

\section{Capsule summary (35 words)}

6 The Transient Receptor Potential vanilloid-1 (TRPV1) channel regulates responses to irritant

7 stimuli. We report TRPV1 overexpression in asthmatic airway epithelium most notably in

8 severe disease suggesting its potential as a therapeutic target for uncontrolled asthma.

9

GMA - glycol methacrylate

\section{Abbreviations:}

TRP - Transient Receptor Potential

qPCR - Quantitative real-time PCR

TRPV1 - Transient Receptor Potential Vanilloid-1

GINA - Global Initiative for Asthma Guidelines

PBEC - Primary bronchial epithelial cell 
2 During an exacerbation of asthma, the airways become hypersensitive and patients are

3 often troubled with bouts of cough and wheeze following exposure to relatively innocuous

4 stimuli such as aerosols, strong odours or changes in air temperature. The precise

5 mechanism for this airway hypersensitivity is not known but upregulation of receptors responsible for sensing chemical and physical stimuli may be relevant. The recently described Transient Receptor Potential (TRP) proteins, a family of $\mathrm{Ca}^{2+}$ permeable non selective cation channels which sense a vast array of chemical and physical stimuli $(1,2)$, are believed to have an important role in the regulation of airway function in both health and disease $(3,4)$. Recent data has provided genetic evidence for the involvement of one subfamily member, TRP vanilloid 1 (TRPV1) in asthma pathophysiology (5).

TRPV1 is activated by capsaicin (the pungent principle contained in hot chilli peppers) and inhaled capsaicin causes cough (6) and bronchospasm (7) in asthmatics. The airway inflammatory events which accompany an exacerbation of asthma include a rise in airway temperature (8), acidosis (9) and release of mediators derived from lipoxygenase metabolism of arachidonic acid $(4,10)$. TRPV1 is primarily recognised as a heat thermal sensor, but it is also readily activated by low extracellular $\mathrm{pH}(11,12)$ and lipoxygenase products such as leukotriene $B_{4}$. (13). TRPV1 receptors are expressed in several cell types in human airway including sensory neurones (14), smooth muscle cells (15) and epithelial cells from both the upper (16) and lower airway (17). As the bronchial epithelium has an important role in sensing and responding to noxious stimuli we hypothesised that TRPV1 is 
1 treat asthma. Further we considered that the inflammatory response following irritant

2 activation of airway epithelial TRPV1 may contribute to heighted neuronal reflexes

3 responsible for cough and bronchospasm in asthma.may .

$4 \quad$ In this study, we examined both TRPV1 expression and function in human bronchial

5 epithelium. In addition we provide evidence for the overexpression of TRPV1 in the airways

6 of severe asthmatics compared to mild asthmatics and healthy subjects. Some of the results

7 of these studies have been reported in abstract form (18).

METHODS AND MATERIALS

Full methodological details are provided in an online data repository

Study Subjects

Participants with refractory asthma were recruited from the Belfast City Hospital. All had persisting symptoms despite treatment at Step 4 or 5 of the Global Initiative for Asthma (GINA) guidelines. Mild to moderate asthmatics had a clinical diagnosis of asthma with a current history of recurrent wheezing and documented response to asthma medication. Bronchial biopsy samples from this Belfast cohort were analysed using immunohistochemistry (IHC). For examination of in vivo gene expression of TRPV1 in airway epithelium an additional cohort of subjects from Leicester were recruited. Demographic details of both cohorts are shown in Table 1. To investigate the functional role of TRPV1, primary bronchial epithelial cell (PBEC) cultures were grown from bronchial brushings obtained from mild asthmatics and non-asthmatic patients recruited from a specialist cough 
1 clinic (19) and healthy participants recruited by advertisement. Demographic details are

2 shown in Table 2.

3 The study was approved by the appropriate Institutional Research Ethics Committees (details in

4 online data repository). Written informed consent was gained from all participants prior to their

5 involvement.

All asthmatic participants were clinically stable at the time of bronchoscopy, and had an $\mathrm{FEV}_{1}>60 \%$ predicted. Bronchial biopsies and brushings were obtained from segmental airways using a standard techniques. Three biopsies from each participant (Belfast Cohort) were submitted for immunohistochemistry studies. Gene expression microarray analysis (and qPCR) was performed on fresh bronchial brushings (Leicester cohort). To investigate the functional role of TRPV1, PBEC cultures from bronchial brushings were cultured as described previously (20). These were obtained from mild asthmatic $(n=4)$, non asthmatic patients with chronic cough $(n=4)$ and healthy volunteers $(n=4)$.

Immunohistochemistry

Twenty eight biopsies (10 healthy volunteer, 8 mild asthmatic and 10 severe asthmatic biopsies) were processed for immunohistochemistry (IHC) using local protocols as detailed in the online data repository. For TRPV1 and ER co-localisation experiments local protocols were employed as detailed in the online data repository. 
2

3

4

5

6

7

\section{Bronchial brushings and PBEC cultures}

Real-time PCR (qRT-PCR) analyses were performed using RNA from bronchial brushings using TaqMan ${ }^{\circledR}$ Gene Expression Assays (Applied Biosystems, Foster City, CA) as previously described (21). RNA was amplified (Ambion,) for Agilent (Santa Clara, CA) two color Whole Human Genome (WHG) 4x44k gene expression microarray analysis.

PBECs were trypsinised and total RNA extracted using the RNeasy Mini Kit (Qiagen, Hilden, Germany) and qRT-PCR performed using a 7300 Real Time PCR system (Applied Biosystems, Foster City, CA). More information including detail on GAPDH and TRPV1 forward and reverse primers is provided in the online data repository.

\section{Western Blotting}

Protein concentration was determined using BCA protein assay kit (Thermo Scientific, Wilmington, USA) and protein expression determined using a rabbit polyclonal TRPV1 antibody (ab63083; Abcam, Cambridge, UK), at a dilution of 1:3000 followed by incubation for $1 \mathrm{~h}$ with the secondary antibody, HRP-labelled anti-rabbit (1:3000; Bio-Rad Laboratories, Hercules, CA, USA). More details provided in online data repository.

\section{TRPV1 agonists / antagonist experiments in PBECs}

Capsaicin is a selective TRPV1 agonist and in this study cultured PBECs were treated with either 10, 25 or $50 \mu \mathrm{M}$ capsaicin or control medium for $24 \mathrm{~h}$ and the concentration of IL-8 measured by ELISA ( $R$ \& D Systems Europe Abingdon, UK). For the antagonist experiments, PBECs were pretreated for 20 min with $10 \mu \mathrm{M}$ of the selective TRPV1 antagonist capsazepine.

\section{Patch clamp experiments}


1 Whole-cell currents were recorded using borosilicate heat-polished patch pipettes (2-3 M $\Omega$

2 resistance when filled with the pipette solution) and an Axopatch 200B amplifier (Molecular

3 Devices, Union City, CA, USA) interfaced to Digidata 1322A using the pClamp 9 software

4 (Molecular Devices) as previously described by ourselves (22) and detailed in the online data

5 repository.

6

7

Data Analysis

Data are presented as means \pm SEM. For statistical analysis a one way ANOVA was performed with Bonferroni test for multiple comparisons. Kendall's tau b statistical analysis was used to examine the trend in biopsy expression by participant group. Patch clamp data were analysed and plotted using Origin 8 (OriginLab, Northampton, MA, USA). A P value $<0.05$ was considered significant.

\section{RESULTS}

\section{Confirmation of TRPV1 expression in cultured human bronchial epithelial cells.}

Gene expression for multiple members of the TRPV family including TRPV1 (but not TRPV5) was identified in PBECs from healthy controls $(n=3)$ (Figure 1A). TRPV1 protein was detected at its expected molecular mass of $95 \mathrm{kDa}$ by Western blotting in the same samples (Figure 1B).

Molecular identification and localisation (immunohistochemical expression) of TRPV1 in healthy and asthmatic epithelium

Microarray 
1 Using gene expression microarray analysis of bronchial brush samples from the Leicester

2 cohort we found significantly greater levels of TRPV1 expression (median, IQR) in severe

3 asthmatics $(0.673,0.452-0.761)$ compared to mild/moderate asthmatics $(0.341,0.167-0.538$,

$4 p=0.008)$ and healthy volunteers $(0.322,0.155-0.410, p=0.004)$ (Figure $1 C)$.

Quantitative PCR.

TRPV1 mRNA was detected in all of the epithelial brush samples. There was no difference in

7 median (IQR) relative fold expression of TRPV1 mRNA calculated as Delta Delta $\mathrm{C}_{\mathrm{T}}$ values between groups: $-1.262(-3.598,2.518),(,-2.523(-4.040,1.362)$ and $-1.289(-4.746,1.624)$ in healthy volunteers, mild / moderate asthmatics and severe asthmatics respectively (see Figure E1 in online data repository)

Immunohistochemistry

Immunohistochemistry revealed bronchial epithelial expression of TRPV1 in healthy volunteers, mild/moderate asthmatics and severe asthmatics (Figures 2A, B and C, respectively). Dual labelling immunofluoresence confirmed the expression of TRPV1 on cytokeratin positive epithelial cells (Figures 3 A, B and C). We observed an intracytoplasmic distribution of the TRPV1 and to further characterise this we undertook additional experiments demonstrating immunohistochemistry staining of bronchial epithelial cells positive for TRPV1 (Figure 4A) and ER (Figure 4B) markers. Colocalisation was evident when the images were merged (Figure 4C).

We observed greater TRPV1 expression in asthmatic epithelium compared to healthy

21 subjects (Figure 5; $p=0.001$ ). 
2 Mean membrane capacitance of PBEC was $30.8 \pm 4.3 \mathrm{pF}(n=6)$. In unstimulated cells, only

3 small background currents could be recorded in the whole range of membrane potentials

4 tested, from -100 to $+140 \mathrm{mV}$ (Figure $6 \mathrm{~A}$, left panel). The I-V relationship of the mean

5 background current normalised by the membrane capacitance to account for some

6 variations in cell size is shown in Figure 6B. It should be noted that composition of the

7 external and pipette solutions was such that this facilitated isolation of cation currents but

8 precluded activation of any potassium or calcium-dependent conductances. Capsaicin

9 application $(50 \mu \mathrm{M})$ caused rapid activation of large outwardly rectifying currents (Figure 6A, middle panel), which is the characteristic "biophysical" signature of TRPV1 channels. This

11 effect was completely reversible upon capsaicin wash-out (Figure 6A, right panel).

Corresponding I-V relationships are shown in Figure 6C. The capsaicin-induced currents reversed close to $0 \mathrm{mV}$ indicating their non-selective cation nature.

To investigate the time course of these responses, voltage ramps over the same range of potentials were applied at $10 \mathrm{~s}$ interval. Figure 7A shows a typical response to $50 \mu \mathrm{M}$ capsaicin application consisting of rapid activation and desensitisation in the continuous presence of the agonist, which developed over 2-3 min. The I-V relationships which were measured in this experiment in control, at the peak response and after agonist wash-out are shown in Figure 7B (compare to I-V curves in Fig. 6C measured by voltage steps), while the mean results are summarised in panel $C$. The increase in current amplitude in response to capsaicin was significant $(p=0.007)$.

\section{Membrane responses to reduction of external $\mathrm{pH}$}


1 Reduction of external pH from 7.4 to 6.4 activated inward and outward currents in cells from

2 healthy patients which were partially inhibited by the addition of the selective TRPV1

3 antagonist capsazepine ( $5 \mu \mathrm{M}$; Fig. 8A). The mean capsazepine-sensitive I-V relation (Fig. 8B

$4 \quad n=4$ ) was similar in profile to the capsaicin-dependent currents exhibiting strong outward

5 rectification and reversal close to $0 \mathrm{mV}$.

6

7

8

\section{Functional expression of TRPV1 in cultured human primary bronchial epithelial cells}

\section{Dose-dependent induction of IL-8 release from cultured human PBECS by capsaicin}

Dose-dependent induction of IL-8 release by capsaicin was observed within each study group although there was no significant difference in fold increase in IL-8 between asthmatic and non asthmatic groups which may relate to sample size (data not shown). The dose dependent increase in IL-8 release when data from all three groups was therefore pooled has been presented in figure 9A. When compared to basal a marginal 1.25 -fold increase in IL-8 release was observed following incubation with $10 \mu \mathrm{M}$ capsaicin with significant increases of 1.76 -fold $(p<0.01)$ and 2.15 -fold $(p<0.001)$ compared to basal observed following incubation with 25 and $50 \mu \mathrm{M}$ doses of capsaicin, respectively.

To further test the specificity of the capsaicin effect, we used selective TRPV1 blocker capsazepine. Capsazepine significantly inhibited capsaicin-induced IL-8 release compared to $25 \mu \mathrm{M}$ capsaicin alone $(\mathrm{p}<0.001)$ and compared to $50 \mu \mathrm{M}$ capsaicin alone $(\mathrm{p}<0.001)$. The data for $n=9$ individual experiments is shown in Figure9B. 


\section{DISCUSSION}

3 In this study we have shown for the first time that TRPV1, which is primarily recognised as

4 the major neuronal hot receptor $(23,24)$, is expressed and functional in human bronchial

5 epithelium. In primary bronchial epithelial cell cultures we have shown that pharmacological

6 activation of the TRPV1 channel with capsaicin induces IL-8 release which can be attenuated

7 by pre-treatment with the selective TRPV1 antagonist capsazepine.

Interestingly, TRPV1 expression in the airway was increased in asthmatic subjects compared

to healthy controls with a further increase in subjects with refractory asthma. Thus, overexpression may have a role in symptoms associated with irritant exposure in asthma, particularly in patients with persisting symptoms despite treatment with high dose antiinflammatory therapy. Understanding the role of TRPV1 in refractory asthma may therefore identify a novel target for anti-inflammatory therapy in more severe disease.

We believe that bronchial epithelial TRPV1 channels are ideally positioned to detect chemical and physical irritants (e.g. inflammatory mediators, environmental pollutants, acid $\mathrm{pH}$ and changes in temperature) in the airway lumen. To date, most of the focus has been on neuronal TRPV1 in the human airway $(14,25)$. However, TRPV1 expression has been reported in a variety of non-neuronal tissues and therefore we hypothesised that the airway responses to environmental stimuli might in part be regulated by the bronchial epithelial TRPV1 receptors. Recent studies in immmortalised airway epithelial cell lines provide some support for this $(17,26)$ although evidence in human disease is lacking. Here we provide in 
1 vivo and ex vivo evidence of TRPV1 expression and function in human airway biopsies and

2 cultured primary bronchial epithelial cells with specific relevance to refractory asthma.

3 We observed an intracytoplasmic distribution of the receptor in bronchial epithelial cells as

4 observed in other cell types $(27,28)$. Our finding of TRPV1 staining in the endoplasmic

5 reticulum is consistent with its functional role as a $\mathrm{Ca}^{2+}$ store release channel regulating

6 intracellular $\mathrm{Ca}^{2+}$ homeostasis. Robust membrane current responses to the TRPV1 agonist

7 capsaicin (Figs. 5 and 6) suggest strongly that plasmalemmal TRPV1 is also expressed and

8 functional in PBEC. We also observed TRPV1 staining on a number of submucosal cells

9 although the focus of this present study is confined to the bronchial epithelial expression.

10 Previous studies from chronic coughers (14) and healthy subjects (15) have reported only sparse TRPV1 expression in the airway epithelium, although greater expression in the upper airway (29). Differences in tissue processing, antibodies used and clinical phenotype may explain the discrepancy. In our studies to evaluated the functional properties of TRPV1 on bronchial epithelium. we saw that PBECs responded to the TRPV1 agonist capsaicin with the release of pro-inflammatory mediators which was blocked by capsazepine, a TRPV1 selective antagonist. Capsaicin induced IL-8 release has been previously observed in both human esophageal (30) and human corneal epithelial cells (31) but not before in culturedPBECs. As IL-8 is known to induce and maintain neural sensitization $(32,33)$ our data provide a mechanistic link whereby activation of bronchial epithelial TRPV1 by environmental irritants or changes in airway $\mathrm{pH}$ or temperature (during exacerbations) may sensitize airway sensory neurones and contribute to the airway and cough hypersensitivity that characterises asthma. 
1 Studies in immortalised respiratory cell lines suggest airway epithelial TRPV1 regulates cell

2 apoptosis in response to environmental irritants (34). Here, we provide the first evidence of

3 a functional airway epithelial TRPV1 channel in primary cells. In the whole-cell patch clamp

4

5 experiments on PBECs ourresults provide direct evidence for the presence of functional TRPV1 in the plasma membrane that can mediate membrane depolarisation and calcium influx; steps which are necessary for release of pro-inflammatory mediators (35). Both kinetics and voltage-dependent properties of capsaicin-induced currents in PBEC are consistent with TRPV1 biophysical features, such as slow activation/deactivation and strong outward rectification.

TRP channels have the capacity to sense a vast range of stimuliand their role in airways disease is currently under intense investigation (1). In our immunohistochemical studies we have shown that TRPV1 is over expressed in the bronchial epithelium of asthmatics compared to healthy subjects and patients with refractory asthma express more epithelial TRPV1 than those with mild/moderate asthma. This was supported by our microarray analysis confirming increased expression of TRPV1 genes in the more severe asthmatics. Although on quantitative PCR, mRNA was not concordant with protein abundance, it has become increasingly clear that at the genomic level, mRNA expression does not consistently predict corresponding protein levels $(36,37)$. This may because of complex posttranscriptional and translational modification and /or that different biological mRNA and protein degradation rates may affect correlation. Post translational modification of TRPV1 has been described in experimentally induced tissue injury (38) and therefore may occur in the inflamed asthmatic airway. 
1 While the vast majority of asthmatics respond to standard doses of current treatments (in

2 particular corticosteroids), a proportion remain symptomatic despite treatment at GINA

3 Step 4/5 and are considered to have difficult or treatment refractory asthma. Our finding

4 that bronchial epithelial TRPV1 is over expressed in refractory (steroid-resistant) asthma

5 suggests its activation may represent a novel pro-inflammatory pathway. Clinical trials of

6 TRP receptor antagonists have been undertaken in other abnormal hypersensitive states

7 including neuropathic pain and these drugs may prove effective in improving symptom

8 control in asthma as well.

9 Our findings suggest that the bronchial epithelium may sense and respond to environmental

10 stimuli via TRPV1 activation. However it is not clear how bronchial epithelial cells signal to

11 afferent sensory nerves. We suggest that release of sensitizing mediators such as IL-8 may

12 be one such mechanism. Such mediators may enhance and augment neurogenic

13 inflammation and nociceptive signalling. Therefore, pharmacological modulation of this

14 receptor may be useful in the treatment of uncontrolled asthma.

\section{ACKNOWLEDGEMENTS}

SS was supported by a grant from Northern Ireland Chest Heart \& Stroke and LP was supported by a grant from Higher Education Authority (North South Research Programme).

Work in Leicester and Belfast was supported in part by grants from Genentech,Inc., South San Francisco, CA, USA 
1 Author contributions: $C B, S A$ and SMCQ performed immunostaining, analysed the data and

2 contributed to the writing of the manuscript. SS and HA performed cell culture, molecular analysis of

3 samples and subsequent ELISAs. DC and JA performed and analysed the gene expression data,

4 analysed the data and contributed to the writing of the manuscript. CB, LH and PB recruited subjects,

5 performed bronchoscopy on the asthmatic subjects. LMG and LP recruited subjects for bronchial

6 brush sampling and with TJW performed the bronchoscopies. LH supervised CB and LMG and RC

7 supervised LP. AZ and MMcG performed and analysed patch-clamp experiments. LMG, AZ and ME

8 supervised SS. LMG and LH conceived and designed the research, contributed to data analysis and

9 interpretation and drafted the original manuscript. All authors approved the final manuscript. 
(1) Nilius B. TRP channels in disease. Biochim Biophys Acta 2007;1772:805-812.

(2) Venkatachalam K, Montell C. TRP channels. Annu Rev Biochem 2007;76:387-417.

(3) Bessac BF, Jordt SE. Sensory detection and responses to toxic gases: mechanisms, health effects, and countermeasures. Proc Am Thorac Soc 2010;7:269-277.

(4) Jia Y, Lee LY. Role of TRPV receptors in respiratory diseases. Biochim Biophys Acta 2007;1772:915-927.

(5) Cantero-Recasens G, Gonzalez JR, Fandos C, Duran-Tauleria E, Smit LA, Kauffmann F, et al. Loss of function of transient receptor potential vanilloid 1 (TRPV1) genetic variant is associated with lower risk of active childhood asthma. J Biol Chem 2010;285:27532-27535.

(6) Doherty MJ, Mister R, Pearson MG, Calverley PM. Capsaicin responsiveness and cough in asthma and chronic obstructive pulmonary disease. Thorax 2000;55:643-649.

(7) Hathaway TJ, Higenbottam TW, Morrison JF, Clelland CA, Wallwork J. Effects of inhaled capsaicin in heart-lung transplant patients and asthmatic subjects. Am Rev Respir Dis 1993;148:1233-1237.

(8) Paredi P, Kharitonov SA, Barnes PJ. Faster rise of exhaled breath temperature in asthma: a novel marker of airway inflammation? Am J Respir Crit Care Med 2002;165:181-184.

(9) Hunt JF, Fang K, Malik R, Snyder A, Malhotra N, Platts-Mills TA, et al. Endogenous airway acidification. Implications for asthma pathophysiology. Am J Respir Crit Care Med 2000;161:694-699.

(10) Dahlen SE, Hedqvist P, Hammarstrom S, Samuelsson B. Leukotrienes are potent constrictors of human bronchi. Nature 1980;288:484-486.

(11) Geppetti P, Trevisani M. Activation and sensitisation of the vanilloid receptor: role in gastrointestinal inflammation and function. Br J Pharmacol 2004;141:1313-1320.

(12) Dhaka A, Uzzell V, Dubin AE, Mathur J, Petrus M, Bandell M, et al. TRPV1 Is Activated by Both Acidic and Basic pH. J Neurosci 2009; 29: 153-158. receptors by products of lipoxygenases: endogenous capsaicin-like substances. Proc Natl Acad Sci U S A 2000;97:6155-6160. 
(14) Groneberg DA, Niimi A, Dinh QT, Cosio B, Hew M, Fischer A et al. Increased expression of transient receptor potential vanilloid-1 in airway nerves of chronic cough. Am J Respir Crit Care Med 2004;170:1276-1280.

(15) Mitchell JE, Campbell AP, New NE, Sadofsky LR, Kastelik JA, Mulrennan SA, et al. Expression and characterization of the intracellular vanilloid receptor (TRPV1) in bronchi from patients with chronic cough. Exp Lung Res 2005;31:295-306.

(16) Yamamoto Y, Taniguchi K. Immunolocalization of VR1 and VRL1 in rat larynx. Auton Neurosci 2005;117:62-65.

(17) Agopyan N, Bhatti T, Yu S, Simon SA. Vanilloid receptor activation by 2- and 10-microm particles induces responses leading to apoptosis in human airway epithelial cells. Toxicol Appl Pharmacol 2003;192:21-35.

(18) Butler CA, McQuaid S, Warke T, Stevenson M, Heaney LG, McGarvey L. The Sensory Receptor TRPV1 Is Expressed In Human Bronchial Epithelium And Upregulated In Refractory (Steroid Resistant) Asthma [abstract]. American Journal of Respiratory and Critical Care Medicine : An Official Journal of the American Thoracic Society, Medical Section of the American Lung Association 2010;181:A2490.

(19) McGarvey LP, Heaney LG, Lawson JT, Johnston BT, Scally CM, Ennis M, et al. Evaluation and outcome of patients with chronic non-productive cough using a comprehensive diagnostic protocol. Thorax 1998;53:738-743.

(20) Doherty GM, Christie SN, Skibinski G, Puddicombe SM, Warke TJ, de Courcey F et al. Non-bronchoscopic sampling and culture of bronchial epithelial cells in children. Clin Exp Allergy 2003;33:1221-1225.

(21) Choy DF, Modrek B, Abbas AR, Kummerfeld S, Clark HF, Wu LC et al. Gene expression patterns of Th2 inflammation and intercellular communication in asthmatic airways. $J$ Immunol 2011;186:1861-1869.

(22) Otsuguro Ki, Tang J, Tang Y, Xiao R, Freichel M, Tsvilovskyy V,et al. Isoform-specific inhibition of TRPC4 channel by phosphatidylinositol 4,5-bisphosphate. J Biol Chem 2008; 283: 10026-10036.

(23) Venkatachalam K \& Montell C. TRP Channels. Annual Review of Biochemistry 2007; 76: 387-417.

(24) Vriens J, Appendino G, \& Nilius B. Pharmacology of Vanilloid Transient Receptor Potential Cation Channels. Mol Pharmacol 2009; 75: 1262-1279. 
(25) Watanabe N, Horie S, Spina D, Michael GJ, Page CP, Priestley JV. Immunohistochemical localization of transient receptor potential vanilloid subtype 1 in the trachea of ovalbuminsensitized Guinea pigs. Int Arch Allergy Immunol 2008;146 Suppl 1:28-32.

(26) Veronesi B, Oortgiesen M, Roy J, Carter JD, Simon SA, Gavett SH. Vanilloid (capsaicin) receptors influence inflammatory sensitivity in response to particulate matter. Toxicol Appl Pharmacol 2000;169:66-76.

(27) Lazzeri M, Vannucchi MG, Zardo C, Spinelli M, Beneforti P, Turini D, et al. Immunohistochemical evidence of vanilloid receptor 1 in normal human urinary bladder. Eur Urol 2004;46:792-798.

(28) Olah Z, Karai L, ladarola MJ. Protein kinase C(alpha) is required for vanilloid receptor 1 activation. Evidence for multiple signaling pathways. J Biol Chem 2002;277:35752-35759.

(29) Seki N, Shirasaki H, Kikuchi M, Sakamoto T, Watanabe N, Himi T. Expression and localization of TRPV1 in human nasal mucosa. Rhinology 2006;44:128-134.

(30) Ma J, Altomare A, Guarino M, Cicala M, Rieder F, Fiocchi C, Li D, et al. HCl-induced and ATP-dependent upregulation of TRPV1 receptor expression and cytokine production by human esophageal epithelial cells. Am J Physiol Gastrointest Liver Physiol 2012 1;303(5):G635-45..

(31) Wang Z, Yang Y, Yang H, Capó-Aponte JE, Tachado SD, Wolosin JM, et al. NF-kB feedback control of JNK1 activation modulates TRPV1-induced increases in IL-6 and IL-8 release by human corneal epithelial cells. Mol Vis. 2011;17:3137-46.

(32) Sachs D, Cunha FQ, Poole S, Ferreira SH. Tumour necrosis factor-alpha, interleukin1 beta and interleukin-8 induce persistent mechanical nociceptor hypersensitivity. Pain 2002;96:89-97.

(33) Uçeyler N, Kafke W, Riediger N, He L, Necula G, Toyka KV, et al. Elevated proinflammatory cytokine expression in affected skin in small fiber neuropathy. Neurology. 2010 Jun 1;74(22):1806-13.

(34) Agopyan N, Head J, Yu S, Simon SA. TRPV1 receptors mediate particulate matterinduced apoptosis. Am J Physiol Lung Cell Mol Physiol 2004;286:L563-72.

(35) Karai LJ, Russell JT, ladarola MJ, Olah Z. Vanilloid receptor 1 regulates multiple calcium compartments and contributes to $\mathrm{Ca} 2+$-induced $\mathrm{Ca} 2+$ release in sensory neurons. J Biol Chem 2004;279:16377-16387.

(36) Guo Y, Xiao P, Lei S, Deng F, Xiao GG, Liu Y, et al. How is mRNA expression predictive for protein expression? A correlation study on human circulating monocytes. Acta Biochim Biophys Sin. 2008;40(5):426-36. 
(37) Chen G, Gharib TG, Huang CC, Taylor JM, Misek DE, Kardia SL, Giordano TJ et al. Discordant protein and mRNA expression in lung adenocarcinomas. Mol Cell Proteomics 2002, 1: 304-313

(38) Szigeti C, Sántha P, Körtvély E, Nyári T, Horváth VJ, Deák É, Dux M, Gulya K, Jancsó G.Disparate changes in the expression of transient receptor potential vanilloid type 1 receptor mRNA and protein in dorsal root ganglion neurons following local capsaicin treatment of the sciatic nerve in the rat. Neuroscience. 2012 Jan 10;201:320-30. 
1 Table 1. Demographic characteristics of the Asthmatic Participants and Healthy Volunteers (Belfast

2 and Leicester cohorts combined). Comparison with the Healthy Volunteer group ${ }^{\dagger} p<0.001,{ }^{\S} p<0.001$,

$3 \quad$ " $p<0.001,{ }^{* *} p<0.001,{ }^{\S \S} p<0.001,{ }^{\ddagger \ddagger} p<0.05$, "'I" $p<0.001$. Comparison with Mild to Moderate

4 Asthmatics: ${ }^{\dagger} p<0.001,{ }^{\ddagger} p=0.007,{ }^{\S} p<0.001,{ }^{\prime} p<0.001,{ }^{* *} p<0.001,{ }^{+\dagger} p<0.0001,{ }^{\S \S} p<0.05,{ }^{* * *} p<0.001$.

\begin{tabular}{|c|c|c|c|c|}
\hline & $\begin{array}{l}\text { Healthy } \\
\text { Volunteers } \\
(n=22)\end{array}$ & $\begin{array}{l}\text { Mild to Moderate } \\
\text { Asthmatics } \\
(n=30)\end{array}$ & $\begin{array}{l}\text { Severe Asthmatics } \\
(n=31)\end{array}$ & p Value* \\
\hline Age (y), median (IQR) & $30(22-45)$ & $29(24-39)$ & $48(38-54)^{\dagger}$ & $<0.0001$ \\
\hline Sex, M/F & $10 / 12$ & $14 / 16$ & $22 / 9$ & 0.09 \\
\hline $\begin{array}{l}\text { Duration of asthma }(y) \text {, } \\
\text { mean } \pm \text { SD }\end{array}$ & N/A & $12 \pm 10$ & $22 \pm 15^{\ddagger}$ & 0.007 \\
\hline Atopy, (n) & 11 & 21 & 23 & 0.16 \\
\hline $\mathrm{FEV}_{1}(\mathrm{~L} / \mathrm{min})$, mean $\pm \mathrm{SD}$ & $3.67 \pm 0.78$ & $3.32 \pm 0.77$ & $2.48 \pm 0.67^{\S}$ & $<0.0001$ \\
\hline $\begin{array}{l}\text { FEV }_{1} \text { (\%predicted), mean } \\
\pm \text { SD }\end{array}$ & $102.8 \pm 11.9$ & $93.5 \pm 16.0$ & $75.9 \pm 16.9^{11}$ & $<0.0001$ \\
\hline $\mathrm{FEV}_{1} / \mathrm{FVC}$, mean \pm SD & $82.1 \pm 9.8$ & $75.9 \pm 10.6$ & $64.6 \pm 11.1^{* *}$ & $<0.0001$ \\
\hline $\begin{array}{l}\text { Inhaled steroid ( } \mathrm{n}) \\
\text { BDP equivalent }(\mu \mathrm{g}) \text {, } \\
\text { median (IQR) }\end{array}$ & $\begin{array}{l}0 \\
0\end{array}$ & $\begin{array}{l}19 \\
400(0-800)\end{array}$ & $\begin{array}{l}31 \\
1600(1200-1600)^{\dagger+}\end{array}$ & $<0.0001$ \\
\hline $\begin{array}{l}\text { Maintenance systemic } \\
\text { steroids }(n)^{b}\end{array}$ & 0 & 0 & $\begin{array}{l}15 \text { (median dose } \\
\text { prednisolone } 5 \mathrm{mg} \\
{[0-10 \mathrm{mg} \text { ] plus } 1} \\
\text { subject maintenance } \\
\text { intramuscular } \\
\text { triamcinolone) }\end{array}$ & \\
\hline Theophylline, (n) & 0 & 1 & 17 & $<0.0001$ \\
\hline $\begin{array}{l}\text { Long-acting } \beta 2 \text {-agonists, } \\
\text { (n) }\end{array}$ & 0 & 14 & 31 & $<0.0001$ \\
\hline Prior smoking & 1 & 5 & 13 & 0.004 \\
\hline
\end{tabular}




\begin{tabular}{|l|l|l|l|l|}
\hline $\begin{array}{l}\text { history (n) } \\
\text { [pack years, median } \\
\text { range] }\end{array}$ & {$[4]$} & {$[1,1-10]$} & {$[2.5,1-20]$} & \\
\hline $\begin{array}{l}\text { Eosinophils (109/L), } \\
\text { median (IQR) }\end{array}$ & $0.1(0.07-0.21)$ & $0.26(0.14-0.45)^{\ddagger \ddagger}$ & $0.49(0.25-0.74)^{\S \S}$ & $<0.0001$ \\
\hline $\begin{array}{l}\text { IgE (kU/L), geometric } \\
\text { mean (95\% confidence } \\
\text { interval) }\end{array}$ & $24.6(13.3-45.8)$ & $\begin{array}{l}159.8(89.8- \\
284.6)^{\mid ! I I}\end{array}$ & $\begin{array}{l}238.5(136.2- \\
417.5)^{* * *}\end{array}$ & $<0.0001$ \\
\hline
\end{tabular}

1 * Calculated by ANOVA with Bonferroni's Multiple Comparisons Test (parametric) or Kruskal-Wallis

2 with Dunn's Multiple Comparison Test (non-parametric) or t-test when only asthma groups

3 compared or Chi-squared for categorical variables (sex, atopy, theophylline, long-acting $\beta 2$-agonists,

4 smoking history).

5

6 
1 Table 2. Demographic characteristics of the mild asthmatic, non-asthmatic cough and healthy

2 volunteers recruited for experiments on cultured primary bronchial epithelial cells.

\begin{tabular}{|c|c|c|c|c|}
\hline & $\begin{array}{l}\text { Healthy volunteers } \\
(n=4)\end{array}$ & $\begin{array}{l}\text { mild asthmatics } \\
(n=4)\end{array}$ & $\begin{array}{l}\text { Non asthmatic } \\
\text { coughers } \\
(n=4)\end{array}$ & $P$ value \\
\hline $\begin{array}{l}\text { Age, (y) } \\
\text { Median (IQR) }\end{array}$ & $35.5(21.3-43.8)$ & $46.0(39.3-56.8)$ & $58.0(45.0-72.5)$ & 0.05 \\
\hline Sex, M/F & $1 / 3$ & $0 / 4$ & $0 / 4$ & 0.336 \\
\hline $\begin{array}{l}\text { Duration of cough } \\
\text { (m) Mean } \pm S D\end{array}$ & $\mathrm{~N} / \mathrm{A}$ & $49.5(30.0)$ & $57.5(27.0)$ & 0.950 \\
\hline $\begin{array}{l}\text { FEV1 (L/min) } \\
\text { Mean } \pm \text { SD }\end{array}$ & $3.45(0.65)$ & $2.52(0.29)$ & $2.3(0.34)^{*}$ & 0.014 \\
\hline $\begin{array}{l}\text { FEV1, \% pred } \\
\text { Mean } \pm \text { SD }\end{array}$ & $107.3(10.59)$ & $105.6(15.23)$ & $118.0(21.28)$ & 0.530 \\
\hline $\begin{array}{l}\text { FEV1/ FVC } \\
\text { Mean } \pm \text { SD }\end{array}$ & $86.6(10.6)$ & $82.73(4.11)$ & $80.2(3.2)$ & 0.446 \\
\hline Atopy $(n)$ & 0 & 0 & 0 & $\mathrm{~N} / \mathrm{A}$ \\
\hline Inhaled steroid (n) & 0 & 4 & 0 & N/A \\
\hline Prior smoking $(\mathrm{n})$ & 0 & 0 & 0 & $\mathrm{~N} / \mathrm{A}$ \\
\hline
\end{tabular}

3 Calculated by ANOVA with Bonferroni's Multiple Comparisons Test (parametric) or Kruskal-Wallis

4 with Dunn's Multiple Comparison Test (non-parametric) or t-test when only cough groups compared

5 or Chi-squared for categorical variables (gender).

6

7

8

9 
Figure 1: A. Molecular expression of TRPV channel subtypes in human primary bronchial epithelial cells. Conventional RT-PCR showing the expression of TRPV family subtypes including TRPV1 in PBECs from healthy controls $(n=3)$

B. Expression of TRPV1 protein in PBECs. TRPV1 specific bands were observed at the molecular weight of $95 \mathrm{KDa}$ in PBECs (lanes 2 to 4, upper panel). TRPV1 transfected HEK cells were used as a positive control (lane

1, upper panel). $\beta$-Tubulin (lower panel) was used to ascertain equal loading (Abcam 6046).

Results are representative of two independent experiments. C. Gene expression microarray analysis of bronchial brush samples from healthy, mild/moderate and severe asthmatics.

Gene expression microarray analysis was performed on fresh bronchial brush samples from the Leicester cohort comprising severe asthmatics ( $n=12)$, mild/moderate asthmatics $(n=16)$ and healthy subjects $(n=8)$. TRPV1 was significantly elevated in severe asthma versus mild moderate asthma $(* p=0.008)$ and healthy volunteers $(* * p=0.004)$.

Figure 2 - Digital photographic images (A-D) of TRPV1 expression in JB4 sections from (A) healthy control: only patchy or focal areas of low intensity epithelial expression; (B) moderate asthmatic: majority of epithelial and submucosal cells express antigen; (C) severe asthmatic: widespread and strong epithelial and submucosal cell expression. Sections incubated in the absence of antibodies showed no staining; a representative image is shown in (D). Representative immunohistochemistry shown at X 400 magnification 
1 Figure 3 - Confocal microscopy images $(A-C)$ of double staining immunocytochemistry

2 demonstrating localisation of TRPV1 channels in bronchial epithelium (healthy subject).

3 Bronchial epithelial cells identified by positive red staining with the cytokeratin antibody

4 AE1AE3 (A) were also positive for the TRPV1 (green) (B) and co-localisation was evident

5 when the images were merged (yellow) (C). Representative immunohistochemistry shown

6 at $\mathrm{X} 400$ magnification

7

Figure 4: TRPV1 and ER colocalisation in human bronchial epithelial cells. Representative confocal microscopy images at X 40 magnification (A-C) showing immunohistochemistry staining of bronchial epithelial cells positive for TRPV1 (A) and ER (B) markers. Colocalisation was evident when the images were merged (C; orange/yellow). DAPI stained blue nuclei (C). Scale bar $=100 \mu \mathrm{m}$.

\section{Figure 5 Quantitative immunohistochemical epithelial expression for TRPV1 in bronchial} biopsies. TRPV1 expression is increased in the bronchial epithelium of severe asthmatic patients. There was a trend to increased TRPV1 expression with severity of asthma $(p=0.001$, Kendall's tau-B statistic).

Figure 6. Whole-cell PBEC (healthy subject) membrane current responses to capsaicin application $(50 \mu \mathrm{M})$ measured by voltage-steps. A. Superimposed current traces evoked by 1 s voltage steps before, in the presence of, and after capsaicin wash-out, as indicated. Dotted line indicates zero-level current. B. Mean normalised I-V relationship of background current 
1 ( $n=4)$. C. I-V relationships for the current amplitude measured at the end of each voltage

2 step in the experiment illustrated in panel A.

3 Figure 7. Time course of the capsaicin membrane current response. A. Current

4 amplitude was monitored by applying voltage ramps from -100 to $140 \mathrm{mV}$ at $10 \mathrm{~s}$ interval.

5 Circles show current amplitude at $140 \mathrm{mV}$. B. The I-V relationships were derived from the

6 ramps applied before, at the peak response and $3 \mathrm{~min}$ after wash-out of the drug as

7 indicated. C. Mean normalised I-V relationships measured before (squares) and after

8 (circles) capsaicin application $(n=3)$. In each cell, current amplitude at $140 \mathrm{mV}$ in control was

9 normalised as 1.0 .

Figure 8. Whole-cell PBEC (healthy subject) membrane current responses to reduced external $\mathrm{pH}$ measured by voltage ramps. A. Superimposed current traces evoked by voltage ramps from -100 to $140 \mathrm{mV}$ at $10 \mathrm{~s}$ interval in $\mathrm{pH} 7.4$ and $\mathrm{pH} 6.4$ ( \pm capsazepine; $5 \mu \mathrm{M}$ ) external solutions as indicated. The dotted line indicates zero-level current. B. Mean \pm SEM I-V relationship (normalized for cell capacitance) of capsazepine-sensitive current $(n=4)$.

Figure 9. Capsaicin induces IL-8 release from human PBECs (asthmatic and non-asthmatic subjects). PBECs treated (24 hours) with 10,25 or $50 \mu \mathrm{M}$ capsaicin or control medium. Values are expressed as the mean release over basal \pm SEM. A. Capsaicin-induced IL-8 release ${ }^{* * *} p<0.001$ compared to control; Kruskal-Wallis test with Dunn's multiple comparison ( $\mathrm{n}=12$ individual experiments). B. Capsazepine inhibits capsaicin induced IL-8 release from human PBECs. PBECs were pre-treated for 20 min with $10 \mu \mathrm{M}$ capsazepine then with 10,25 or $50 \mu \mathrm{M}$ capsaicin or control medium with or without capsazepine. Values are expressed as mean release over basal \pm SEM. Capsazepine significantly inhibited 
1 capsaicin-induced IL-8 release compared to $25 \mu \mathrm{M}\left({ }^{*} \mathrm{p}<0.001\right)$ and and $50 \mu \mathrm{M}\left({ }^{* *} \mathrm{p}<0.001\right)$

2 capsaicin alone; one way ANOVA with Bonferroni's multiple comparison test ( $n=9$ individual

3 experiments).

4

5

6

7

8 
Figure No. 1

Figure 1

A

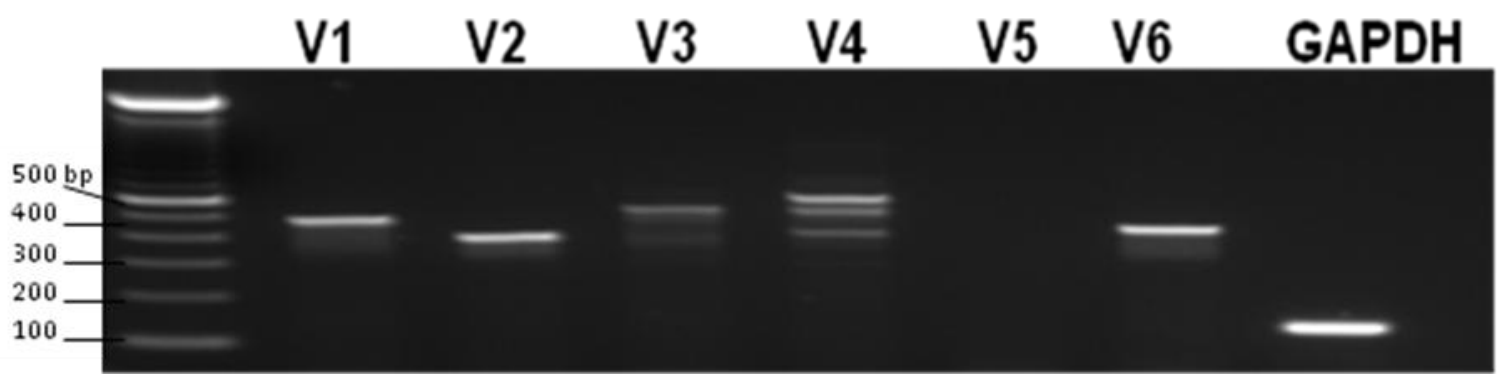

B

$12 \quad 3 \quad 4$

$95 \mathrm{KDa}$

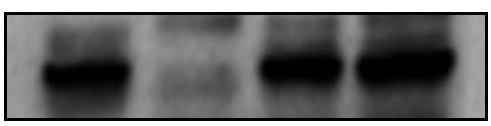

TRPV1 95 kDa

$50 \mathrm{KDa}$

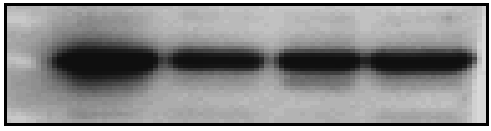

B-Tubulin 50 kDa

C

Gene expression microarray analysis of bronchial brush samples healthy, $\mathrm{mild} /$ moderate and severe asthmatics

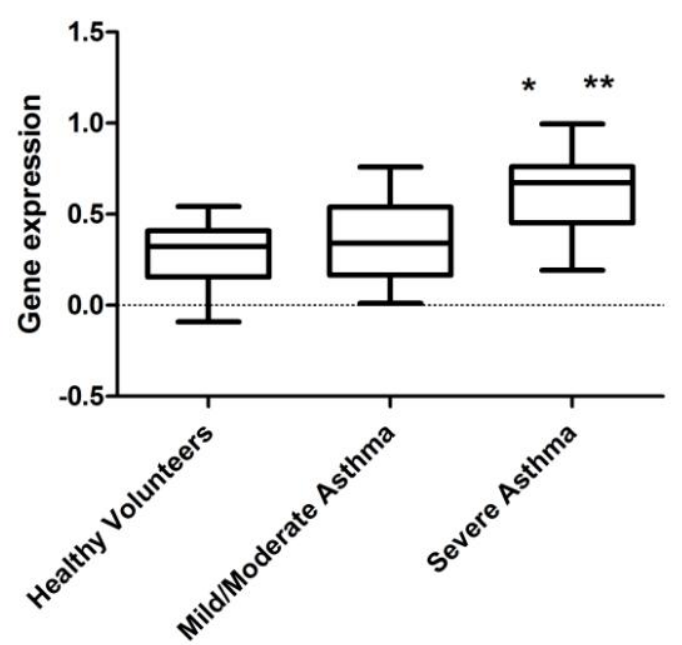


Figure No. 2

Figure 2
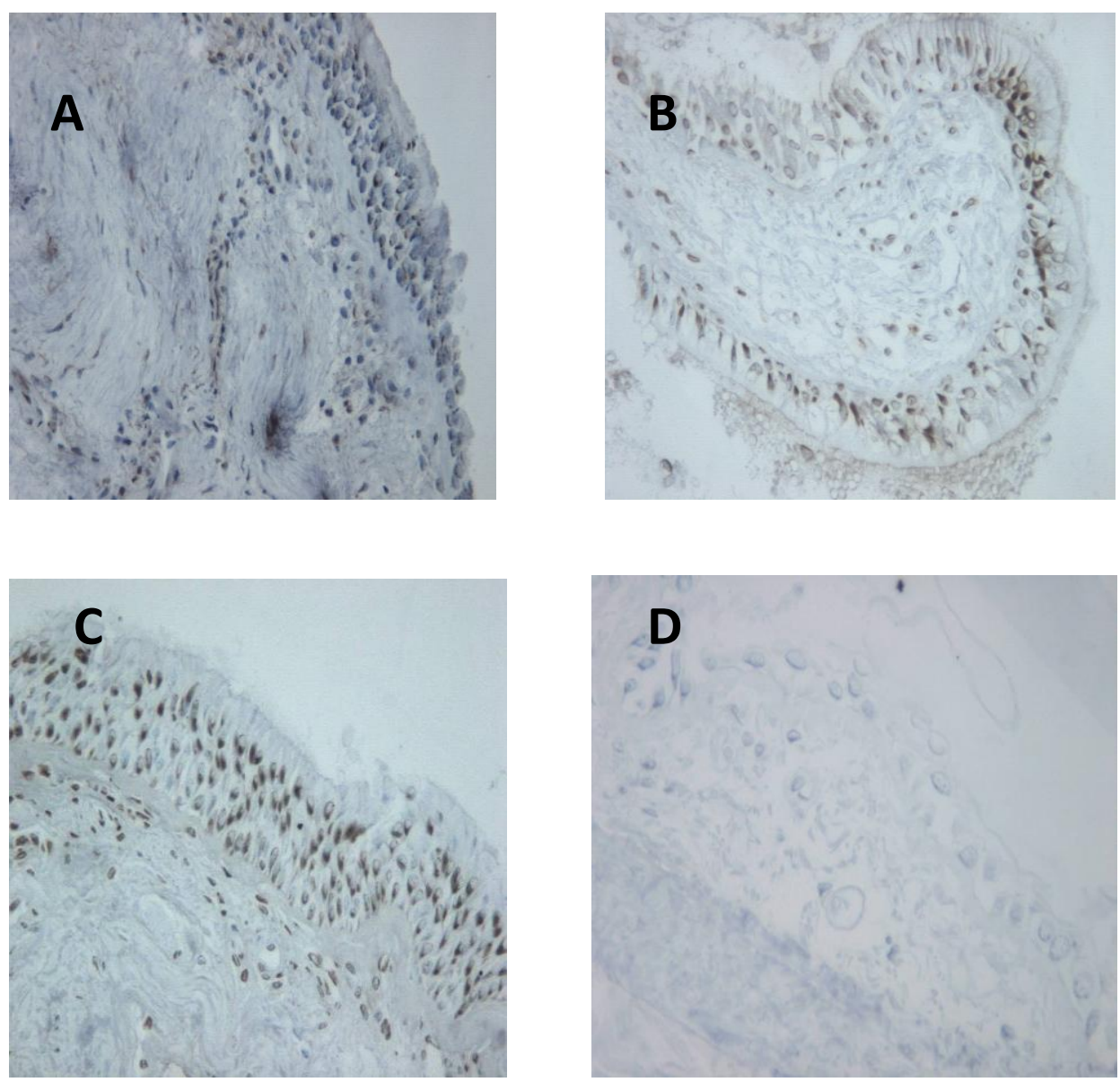
Figure 3
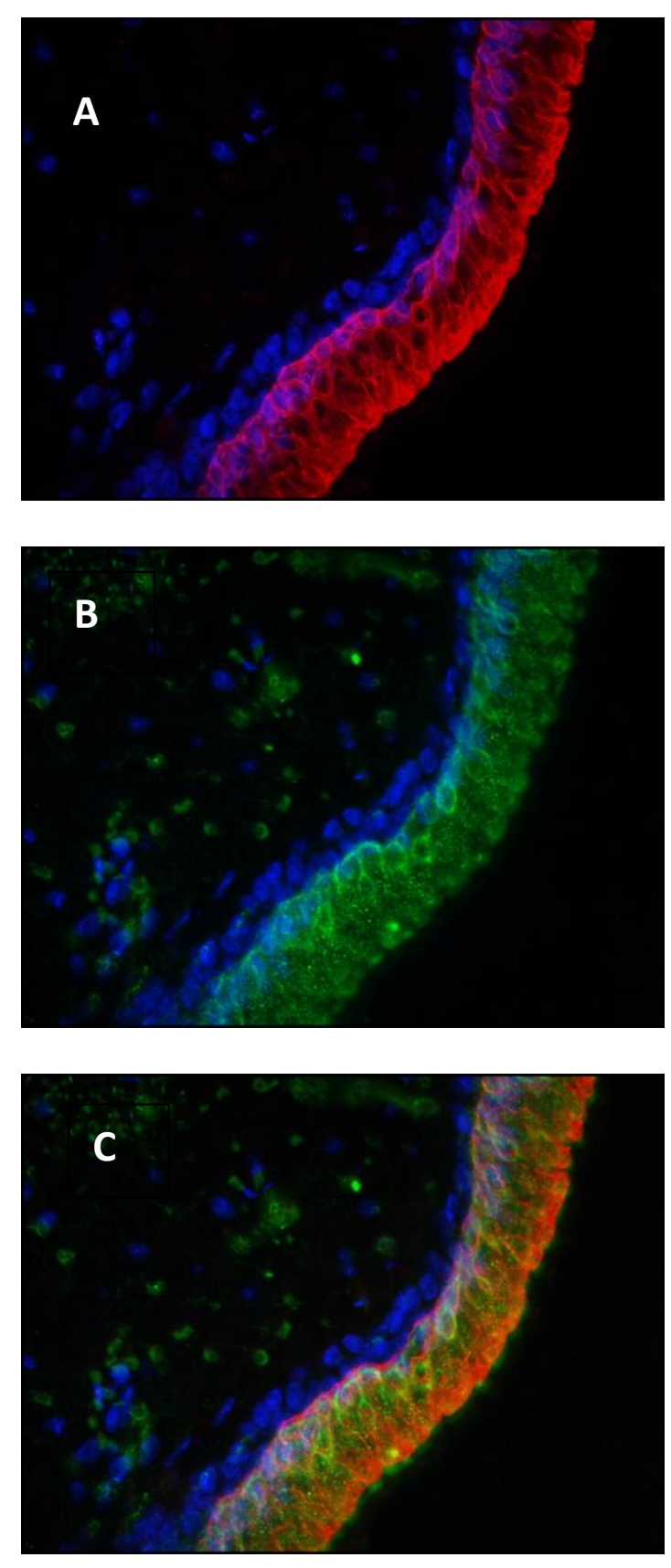
Figure 4

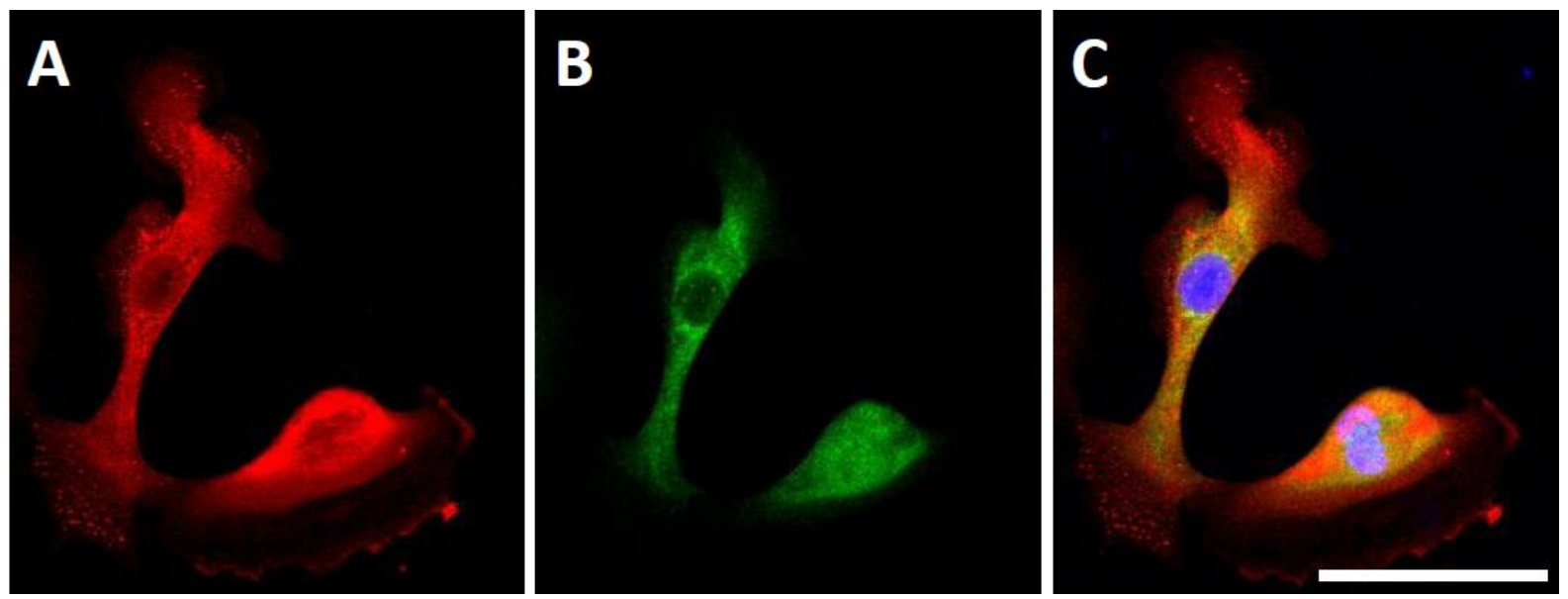


Figure 5

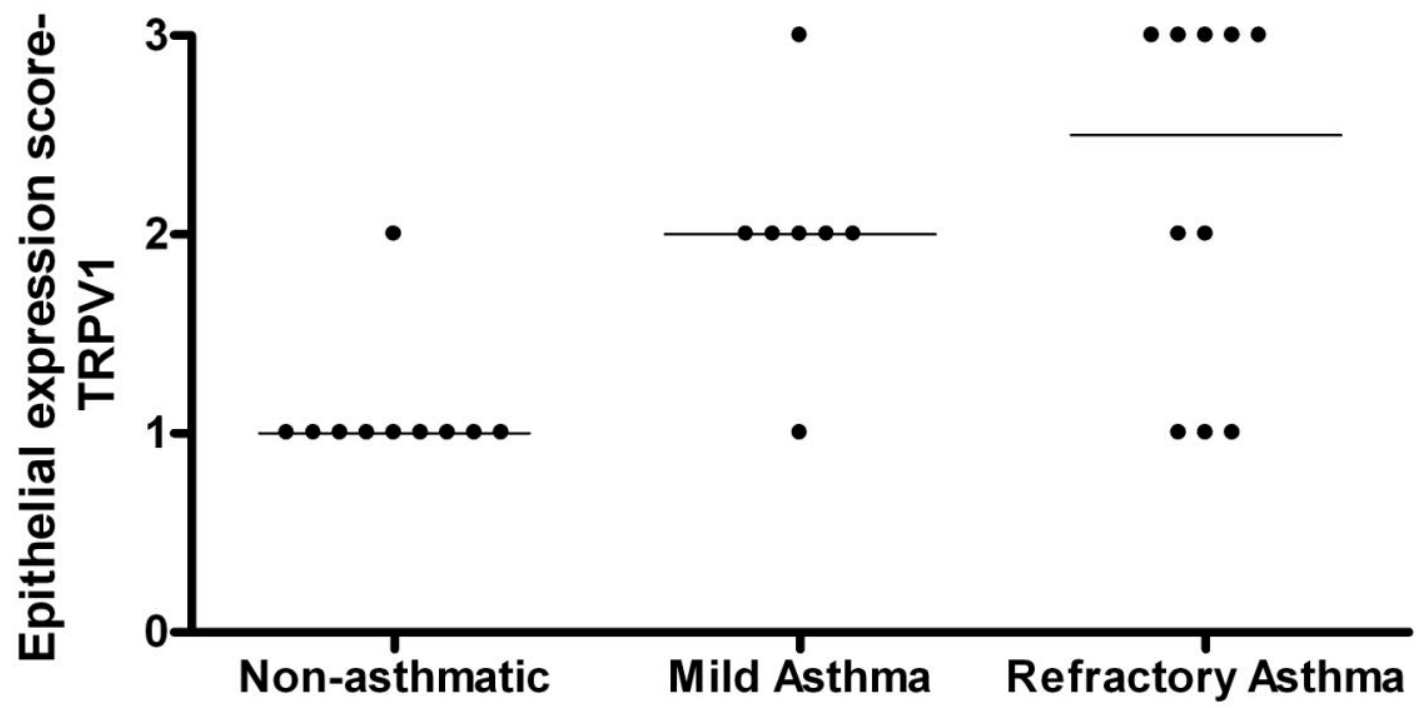


Figure No. 6

Figure 6

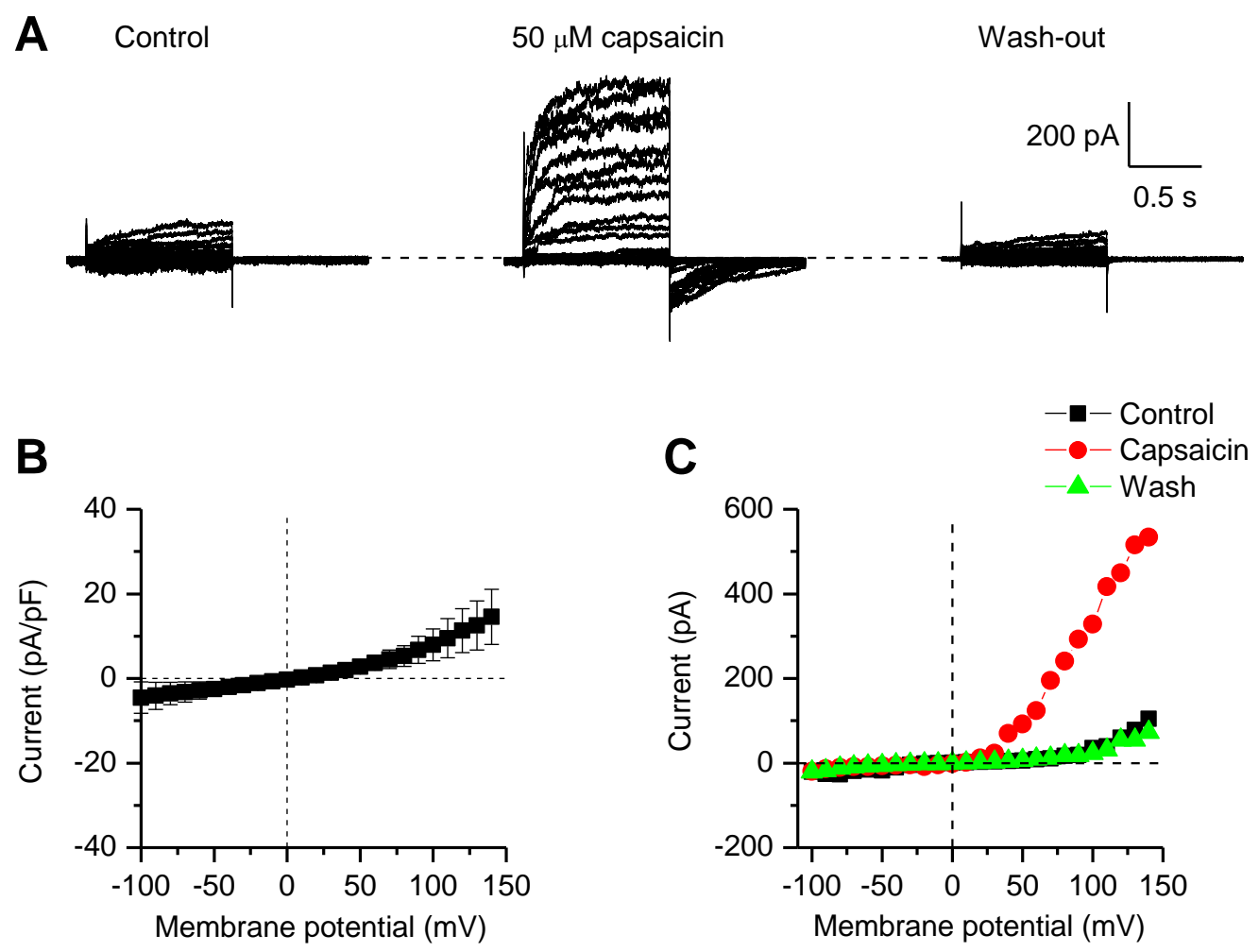


Figure No. 7

Figure 7

A

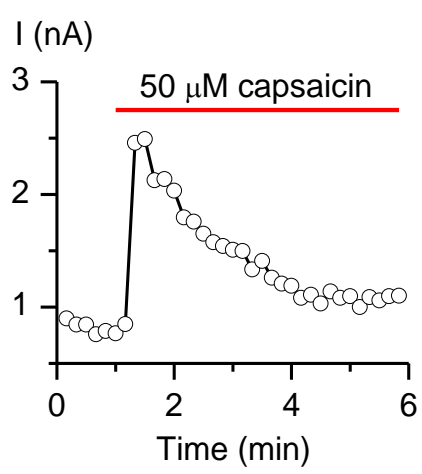

B

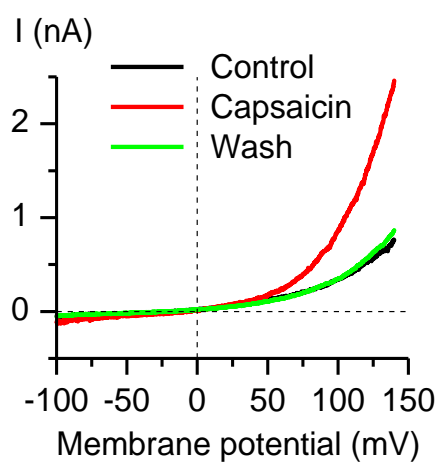

C

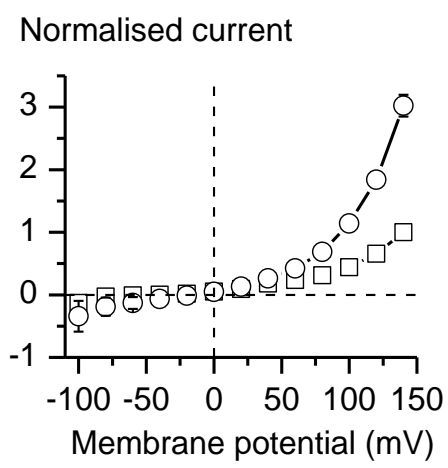


Figure No. 8

Figure 8
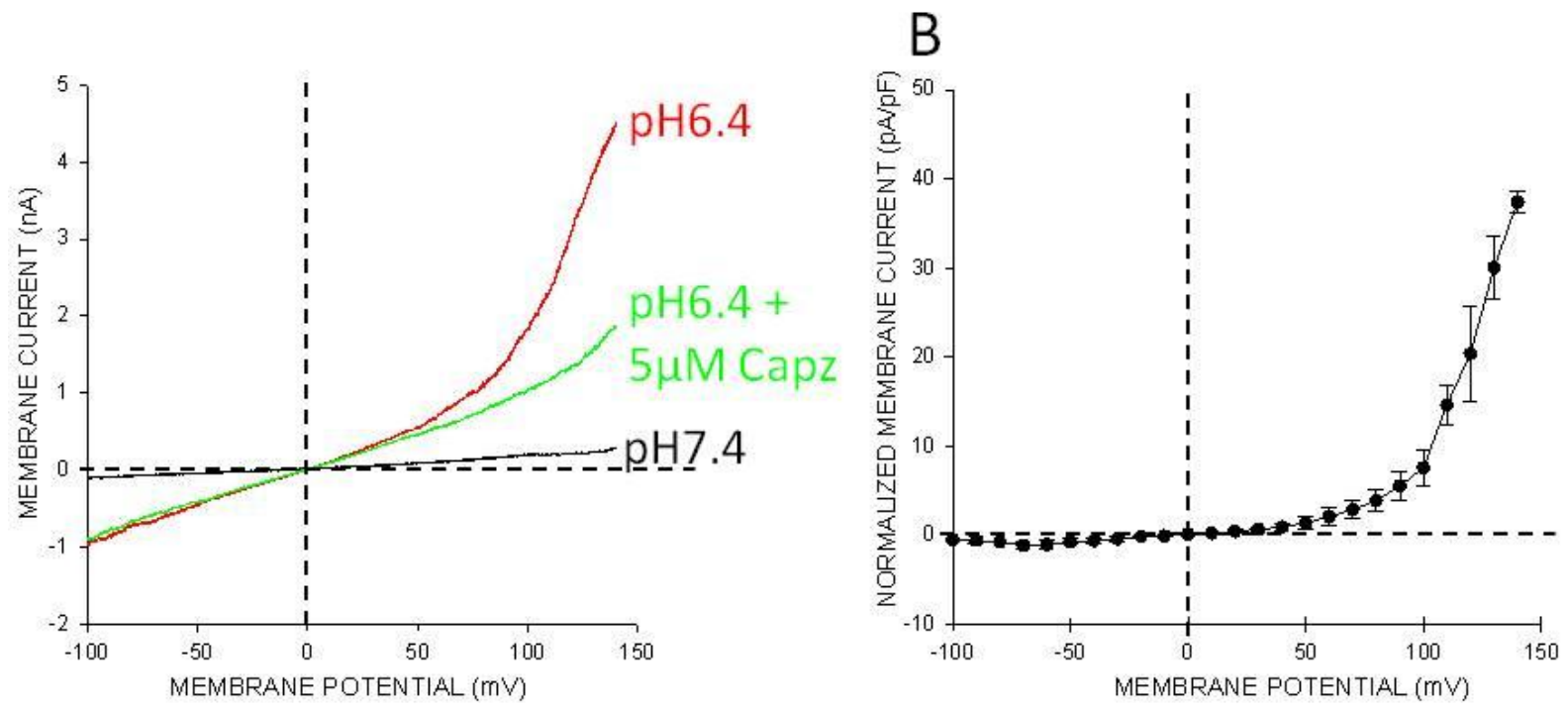
Figure No. 9

Figure 7

A

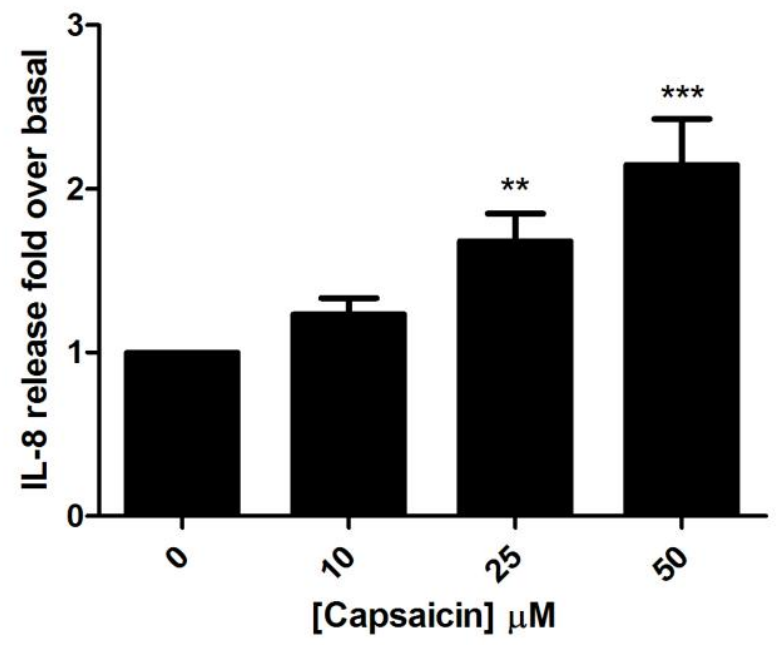

B

$\square+10 \mu \mathrm{M}$ Capsazepine

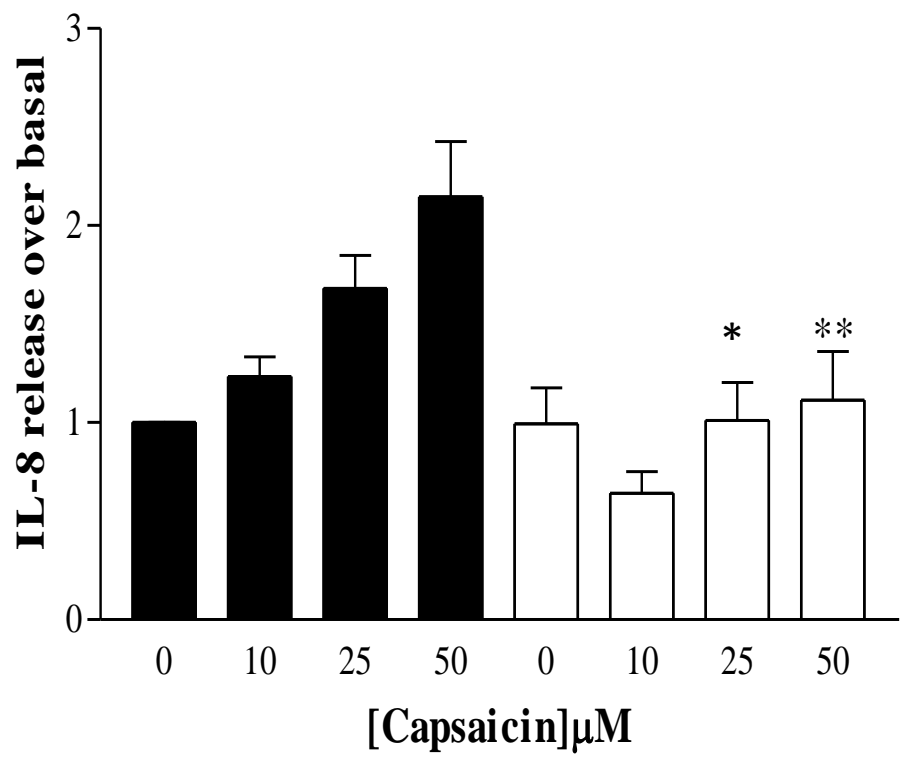




\section{ONLINE DATA REPOSITORY}

\section{Increased expression of bronchial epithelial transient receptor potential vanilloid 1} channels in severe asthma

Lorcan P McGarvey ${ }^{1}$, Claire A Butler ${ }^{1}$, Susan Stokesberry ${ }^{1}$, Liam Polley ${ }^{1}$, Stephen McQuaid ${ }^{2}$, Hani'ah Abdullah' ${ }^{1}$, Sadaf Ashraf ${ }^{3}$, Mary K McGahon ${ }^{3}$, Tim M Curtis $^{3}$, Joe Arron ${ }^{4}$, David Choy ${ }^{4}$, Tim J Warke ${ }^{1}$, Peter Bradding ${ }^{5}$, Madeleine Ennis ${ }^{1}$, Alexander Zholos ${ }^{6}$, Richard Costello ${ }^{7}$ and Liam G Heaney ${ }^{1}$.

${ }^{1}$ Centre for Infection and immunity, Health Sciences Building, Queens University Belfast, Lisburn Road, Belfast, BT9 7BL. UK. ${ }^{2}$ Tissue Pathology, Belfast Health and Social Care Trust, Belfast, BT9 7AB, UK. ${ }^{3}$ Genentech, 1 DNA Way, South San Francisco, California, USA, ${ }^{4}$ Institute for Lung Health, Dept or Infection, Immunity and Inflammation, University of Leicester, Leicester, UK ${ }^{5}$ Centre for Vision and Vascular Science, Queen's University Belfast, UK and Institute of Biology, Taras Shevchenko Kiev National University, Kiev 03022, Ukraine, ${ }^{6}$ Department of Respiratory, Otolaryngology and Molecular Medicine, Education and Research Centre, Smurfit Building, Royal College of Surgeons in Ireland, Dublin 9, Ireland

Corresponding author: Dr Lorcan McGarvey,

Centre for Infection and Immunity, Queens University Belfast. Level 8, Belfast City Hospital, Lisburn Road, Belfast, BT9 7AB

Northern Ireland, UK.

Email: I.mcgarvey@qub.ac.uk 


\section{Study Subjects}

The studies were approved by the Research Ethics Committee of both Institutions (Belfast Office of Research and Ethics Committee of Northern Ireland reference 06/NIR02/114 and 09/NIR02/51, Leicester - Leicestershire, Northamptonshire, \& Rutland Research Ethics Committee reference 04/Q2502/74). Written informed consent was gained from all participants prior to their involvement.

Bronchial biopsies:

Belfast Cohort: Participants with refractory asthma were recruited from the Belfast City Hospital where systematic evaluation protocols ensure patients have well-characterised refractory asthma. All participants had persisting symptoms despite treatment at Step 4 or 5 of the GINA guidelines Global Initiative for Asthma (GINA) (E1). Mild to moderate asthmatic and normal participants were recruited by advertisement and had a clinical diagnosis of asthma with a current history of recurrent wheezing and response to asthma medication. Healthy volunteers had no history of asthma or persistent respiratory symptoms and normal lung function. All asthmatic participants were clinically stable on their usual medication at the time of bronchoscopy, and all participants had an FEV1 of greater than $60 \%$ predicted. Demographic details are shown in Table 1 of the main paper.

Leicester cohort: For the gene expression studies, asthmatic subjects $(n=36)$ and healthy volunteers $(n=12)$ were recruited from respiratory clinics including the Leicester Difficult Asthma Clinic, from staff at Glenfield Hospital, and from the general population through advertisement (Leicester cohort). Subjects with asthma gave a suggestive history and had objective evidence of variable airflow obstruction as indicated by one or more of the 
following: (1) methacholine airway hyperresponsiveness ( $\mathrm{PC}_{20} \mathrm{FEV}_{1}<8 \mathrm{mg} / \mathrm{mL}$ ), (2) $>15 \%$ improvement in $\mathrm{FEV}_{1} 10$ minutes after $200 \mu \mathrm{g}$ inhaled salbutamol, (3) peak expiratory flow (>20\% maximum within-day amplitude from twice-daily peak expiratory flow measurements over a period of 14 days). Subjects underwent spirometry; allergen skin prick tests for Dermatophagoides pteronyssinus, dog, cat, grass pollen and Aspergillus fumigatus; a methacholine inhalation test using the tidal breathing method; and sputum induction using incremental concentrations of nebulized hypertonic saline (i.e., 3\%, 4\%, and 5\%, each for 5 $\min )(E 2)$. Subjects with asthma also kept a diary card for 2 weeks prior to bronchoscopy, recording daytime and night-time symptoms, daily short-acting $\beta_{2}$-agonist use and twice daily peak expiratory flow (PEF). Asthma severity was defined by British Guideline on the Management of Asthma treatment steps (mild = step 1, $\beta_{2}$-agonist only; moderate $=$ steps 2 and 3 , inhaled corticosteroid $\leq 800 \mathrm{mg}$ beclomethasone equivalent per day \pm long-acting $\beta_{2^{-}}$ agonist; severe $=$ step 4 and 5) (E3). Of the 16 severe patients at step 4/5, 13 met the American Thoracic Society criteria for refractory asthma (E4).

In both cohorts, all participants were current non-smokers with no upper or lower respiratory tract infection in the 6 weeks prior to their bronchoscopy. All asthmatic participants were clinically stable on their usual medication at the time of bronchoscopy. Demographic details for each cohort are shown in Table 1 in the main manuscript.

Primary bronchial epithelial cell (PBEC) cultures: To investigate the functional role of TRPV1 we performed a series of experiments on primary bronchial epithelial cell (PBEC) cultures 
from bronchial brushings obtained from mild asthmatic $(n=4)$ and non asthmatic patients with chronic cough $(n=4)$ referred to the Belfast City Hospital specialist cough clinic (E5). Healthy volunteers $(n=4)$ were recruited by local advertisement. Demographic details for this cohort are shown in Table 2 in the main manuscript.

\section{Bronchoscopy and samples}

Bronchoscopy was performed using a standard technique. In brief, after intravenous sedation and local anaesthesia with topical lignocaine, bronchial biopsies and bronchial brushings were obtained from lobar / segmental airways. One biopsy from each participant was immediately placed in RNA preservative (RNAlater, Ambion, Austin, TX) and submitted for microarray analysis and $\mathrm{qPCR}$ and 3 biopsies placed immediately into dry acetone containing protease inhibitors (iodoacetamide and PMSF) and fixed overnight at $-20^{\circ} \mathrm{C}$. Brushings were placed in RNAlater or Promocell ${ }^{\mathrm{TM}}$ medium containing penicillin/streptomycin and Primocin ${ }^{\mathrm{TM}}$ for cell culture (Promocell UK). PBECs were cultured using methods developed in our laboratory which resulted in homogenous cultures of basal epithelial cells (E6).

For immunohistochemistry (IHC), biopsy samples were processed using local protocols. Twenty eight biopsies (10 healthy volunteer, 8 mild asthmatic and 10 severe asthmatic biopsies) were available for immunohistochemistry. Infiltration and embedding with JB4 resin was performed as previously described (E7). Two $\mu \mathrm{m}$ sections were cut from each biopsy. Endogenous peroxidise was blocked with $0.3 \%$ hydrogen peroxide. All sections were pressure cooked in 0.01M Tris-EDTA pH9.0 on full steam for 3 minutes for antigen retrieval. Sections were incubated with TRPV1 polyclonal antibody (1:200, Abcam), overnight at $4^{\circ} \mathrm{C}$, then primary antibodies were detected by incubation for $30 \mathrm{~min}$ at RT in peroxidase-labelled 
EnVision anti-rabbit secondary antibody (Dako, Ely, UK) using 3,3'-diaminobenzidine (DAB;

Dako, Ely, UK) as chromagen. On selected tissue sections from this series, immunofluorescence was carried out to permit high resolution analysis of TRPV1 antigen distribution. Sections were treated as for IHC and following incubation in a mix of TRPV1 and a monoclonal antibody to the epithelial specific antibody AE1AE3 (1:50, Dako). Antigen binding sites were detected with a mixture of anti-mouse Alexa 568 and anti-rabbit Alexa 488 (Invitrogen). Sections were counterstained with DAPI hardset mounting medium (Vector). All fluorescently stained slides were assessed and digital fluorescent images acquired with a Leica DFC350 FX digital camera and processed using Leica FW4000 software. Immunostained sections were evaluated by two independent persons, following which results were discussed and consensus scoring applied to any conflicting results. A 4-point scoring system was used: 0 - no detectable expression in epithelium or submucosa; 1 - patchy or focal areas of low intensity epithelial expression, not all cells expressing positivity for protein, scattered positivity in submucosa; 2 - moderate / majority of epithelial and submucosal cell expression; 3 - widespread and strong epithelial and submucosal cell expression.

\section{TRPV1 and ER colocalisation in human bronchial epithelial cells.}

Human bronchial epithelial cells were grown on coverslips and fixed in $4 \%$ paraformaldehyde (PFA) for 30 minutes at RT. Cells were briefly washed in Phosphate Buffered Saline (PBS) before being permeabilised with 0.1\% Triton X-100 in PBS for 20 minutes at RT. Cells were blocked with 10\% Bovine Serum Albumin (BSA) in PBS for 1 hour at RT and incubated with primary antibodies, mouse monoclonal anti-KDEL (1:500), ER marker and rabbit polyclonal anti-VR1 (1:200), TRPV1 marker (AB12223 and Ab63083 respectively; 
Abcam, Cambridge, UK) overnight at $4^{0} \mathrm{C}$, followed by incubation for 1 hour at RT with secondary antibodies, Alexa Fluor goat anti-mouse 488 (1:500; Invitrogen) and Alexa Fluor goat anti-rabbit 568 (1:500; Invitrogen). Cell nuclei were stained using Vectashield mounting medium containing DAPI (Vector Labs, Peterborough, UK). Staining was visualised and images captured using Nikon EZ-C1 confocal system running C1 acquisition software (Nikon UK Ltd. Surrey, UK) at x40 magnification.

\section{Gene expression analyses}

RNA was isolated from homogenized bronchial biopsies and real-time PCR (qPCR) was performed as described previously (E8). TaqMan ${ }^{\circledR}$ Gene Expression Assays (Applied Biosystems, Foster City, CA) were purchased and conducted per manufacturer's instructions for TRPV1. RNA was amplified (Ambion,) for Agilent (Santa Clara, CA) two color Whole Human Genome (WHG) 4x44k gene expression microarray analysis. Universal Human Reference RNA (Stratagene, La Jolla, CA) was used for the reference channel. Probe intensities were transformed as $\log _{2}$ ratios of test and reference channels calculated by the Agilent Feature Extraction software, protocol GE2-v5_95 (Agilent). Flagged outliers were not included in any subsequent analyses. All gene expression analyses and plotting were performed using the R Project software package, version 2.10 .1 (refer to http://www.Rproject.org). 


\section{Quantitative Real-Time PCR}

Bronchial brushings

Real-time PCR (qRT-PCR) analyses were performed using RNA from homogenized bronchial brushings ( 36 subjects; 10 HV, 16 MA and 15 SA) using TaqMan ${ }^{\circledR}$ Gene Expression Assays (Applied Biosystems, Foster City, CA) as previously described. The delta-delta Ct method was used to calculate relative fold expression with GAPDH as housekeeping gene

\section{PBEC cultures}

PBECs were trypsinised and cells lysed using Qiagen RLT buffer (Qiagen, Hilden, Germany) before homogenisation using QIAshredders (Qiagen, Hilden, Germany). RNA was then extracted using the RNeasy Mini Kit (Qiagen, Hilden, Germany). RNA concentration was measured with the nanodrop spectrophotometer (Thermo Scientific, Wilmington, USA) and $1 \mu \mathrm{g}$ RNA was used to synthesise cDNA using the high capacity cDNA reverse transcription kit (Applied Biosystems, Foster City, CA). PBEC cDNA was mixed with Power Sybr Green PCR master mix (Applied Biosystems, Foster City, CA) and either GAPDH or TRPV1 forward and reverse primers (Table E1). The following PCRs were performed in a 7300 Real Time PCR system (Applied Biosystems, Foster City, CA). Melting curves showed formation of only one gene product per primer pair. Normalisations and calibrations of the data from all studies were performed with the ${\underline{2^{-\Delta \Delta C}}}^{\mathrm{I}}$ method as described in Applied Biosystems User Bulletin No. $2\left(\mathrm{P} / \mathrm{N}\right.$ 4303859) (27). Delta $\mathrm{C}_{T}$ was calculated as target gene expression $\left(\mathrm{C}_{T}\right)$ minus internal housekeeping control, GAPDH gene expression $\left(C_{T}\right)$. Human Universal Reference RNA (Clontech, P/N 639654) was prepared as cDNA and utilised as plate calibrators. DeltaDelta $\mathrm{C}_{\mathrm{T}}$ was calculated as sample Delta $\mathrm{C}_{\mathrm{T}}$ minus plate calibrator Delta $\mathrm{C}_{\mathrm{T}}$. GAPDH and TRPV1 forward and reverse primers are detailed in table E1 below. 


\section{Western Blotting}

PBECs were collected and snap frozen, homogenised and lysed in RIPA buffer supplemented with protease inhibitor cocktail (Roche Diagnostics, Mannheim, Germany). Protein concentration was determined using BCA protein assay kit (Thermo Scientific, Wilmington, USA). $30 \mu \mathrm{g}$ of total protein was separated on the $8 \%$ SDS-Polyacrylamide gel by electrophoresis and transferred to Hybond-P PVDF membrane (GE Healthcare Life Sciences, Buckinghamshire, UK). The membrane was blocked for 30 min in $3 \%$ BSA/ PBS and then probed overnight in 3\% BSA/PBS with a rabbit polyclonal TRPV1 antibody (ab63083; Abcam, Cambridge, UK), at a dilution of 1:3000. Followed by incubation for $1 \mathrm{~h}$ with the secondary antibody, HRP-labelled anti-rabbit (1:3000; Bio-Rad Laboratories, Hercules, CA, USA). Images were obtained using UVP bioimager (UVP, Cambridge, UK). Benchmark Pre-stained protein standards (Invitrogen, Paisley, UK) were used to determine molecular mass.

\section{Patch clamp experiments}

Whole-cell currents were recorded using borosilicate heat-polished patch pipettes (2-3 M $\Omega$ resistance when filled with the pipette solution) and an Axopatch 200B amplifier (Molecular Devices, Union City, CA, USA) interfaced to Digidata 1322A using the pClamp 9 software (Molecular Devices). Series resistance was compensated by about $70 \%$. Holding potential was $-40 \mathrm{mV}$. Steady-state current-voltage (I-V) relationships were measured by applying either voltage steps (test potentials from -100 to $+140 \mathrm{mV}$ with a $20 \mathrm{mV}$ increment) or slow voltage ramps from -100 to $+140 \mathrm{mV}$. To monitor the time course of TRPV1 activation by 
capsaicin, the voltage ramps were applied at $10 \mathrm{~s}$ interval. The I-V curves obtained by the voltage ramp and step protocols were similar confirming steady-state channel activity at each test potential when ramps were used.

For experiments involving the addition of capsaicin the external solution contained $(\mathrm{mM})$ : $\mathrm{NaCl}$ 120, glucose 12, HEPES 10, pH 7.4 (adjusted with $\mathrm{NaOH}$ ). Pipette solution contained (mM): CsCl 80, MgATP 1, creatine 5, GTP 1, D-glucose 5, HEPES 10, BAPTA 10, $\mathrm{CaCl}_{2} 4.6$ $\left(\left[\mathrm{Ca}^{2+}\right]_{i}=100 \mathrm{nM}\right), \mathrm{pH} 7.4$ (adjusted with $\mathrm{CsOH}$ ). For experiments involving altered $\mathrm{pH}$ the external solution contained (mM): $\mathrm{NaCl} 150, \mathrm{CsCl} 6, \mathrm{MgCl}_{2}$ 1.3, $\mathrm{CaCl}_{2}$ 2, Glucose, 5; HEPES, 10; pH7.4 or 6.4 with Tris. Pipette solution contained (mM): CsOH 130, D Gluconic Acid 120, $\mathrm{MgCl}_{2}$ 1, EGTA $0.5\left(\left[\mathrm{Ca}^{2+}\right]_{\mathrm{i}}=30 \mathrm{nM}\right), \mathrm{pH} 7.2$ with Tris.

\section{IL-8 ELISA}

IL-8 concentrations were measured from aliquots of culture medium taken $24 \mathrm{~h}$ following treatment with capsaicin (Enzo Life Sciences, Exeter, UK) using a commercial ELISA kit from R \& D Systems Europe (Abingdon, UK).

Data Analysis

Data are presented as means \pm SEM. For statistical analysis a one way ANOVA was performed with Bonferroni test for multiple comparisons. Kendall's tau b statistical analysis was used to examine the trend in biopsy expression by participant group. Patch clamp data were analysed and plotted using Origin 8 (OriginLab, Northampton, MA, USA). A P value < 0.05 was considered significant.

\section{RESULTS}


Real time PCR (qRT PCR) analysis of fresh bronchial brush samples from the Leicester cohort comprising healthy, mild/moderate and severe asthmatics. Analysis was performed on fresh bronchial brush samples from the Leicester cohort comprising severe asthmatics $(n=15)$, mild/moderate asthmatics $(n=16)$ and healthy subjects $(n=10)$. TRPV1 mRNA was detected in all of the epithelial brush samples. There was no difference in median (IQR) relative fold expression of TRPV1 mRNA calculated as Delta Delta $C_{T}$ values between groups: $-1.262(-3.598,2.518),(,-2.523(-4.040,1.362)$ and $-1.289(-4.746,1.624)$ in healthy volunteers, mild / moderate asthmatics and severe asthmatics respectively (see figure E1 below).

\section{Online Figure Legend}

Figure E1: Real time PCR (qRT PCR) expression of TRPV1 in fresh bronchial epithelial brush samples from healthy volunteers, mild/moderate asthmatics and severe asthmatics.

Analysis of fresh bronchial brush samples from the Leicester cohort comprising healthy $(n=10)$, mild/moderate $(n=16)$ and severe asthmatics $(n=15)$. Data presented as median (IQR) relative fold expression of TRPV1 mRNA calculated as delta delta $C_{T}$ values. 


\section{References}

E1. Global Strategy for Asthma Management and Prevention GINA Executive Summary. Eur Respir J. 2008;31:1-36.

E2. Brightling CE, Ward R, Woltmann G, Bradding P, Sheller JR, Dworski R et al. Induced sputum inflammatory mediator concentrations in eosinophilic bronchitis and asthma. Am J Respir Crit Care Med 2000; 162:878-82.

E3. British Guideline on the Management of Asthma. Thorax 2008; 63:iv1-iv121.

E4. Proceedings of the ATS workshop on refractory asthma . Current understanding, recommendations, and unanswered questions. Am J Respir Crit Care Med 2000; 162:2341-51.

E5. McGarvey L, Heaney LG, Lawson JT, Johnston BT, Scally CM, Ennis M, Shepherd DR, MacMahon J Evaluation and outcome of patients with chronic non-productive cough using a comprehensive diagnostic protocol. Thorax 1998;53:738-743.

E6. Doherty GM, Christie SN, Skibinski G, Puddicombe SM, Warke TJ, de Courcey F, Cross AL, Lyons JD, Ennis M, Shields MD, Heaney LG. Non-bronchoscopic sampling and culture of epithelial cells in children. Clin Exp Allergy. 2003 Sep;33(9):1221-5

E7. Britten KM, Howarth PH, Roche WR. Immunohistochemistry on resin sections: a comparison of resin embedding techniques for small mucosal biopsies. Biotech Histochem. 1993;68(5):27180.

E8. Choy DF, Modrek B, Abbas AR, Kummerfeld S, Clark HF, Wu LC et al. Gene Expression Patterns of Th2 Inflammation and Intercellular Communication in Asthmatic Airways. J Immunol 2010;doi:10.4049/jimmunol.1002568. 
Click here to download Repository E Tables: revTRPV1onlineRepository jg130819orT1.doc

Table E1. Forward and reverse primers for TRPV1 and GAPDH

\begin{tabular}{|l|l|l|l|}
\hline \multicolumn{1}{|c|}{ Primer name } & \multicolumn{1}{|c|}{ Forward } & Reverse & Size (bp) \\
\hline TRPV1 & GCCTGGAGCTGTTCAAGTTC & GCCTGAAACTCTGCTTGACC & 452 \\
\hline TRPV2 & CCAGCTCTCCAGTTTTCAGG & GTTCAGCACAGCCTTCATCA & 365 \\
\hline TRPV3 & TTCCTCATGCACAAGCTGAC & TGCGCTTCACAAAGTCATTC & 490 \\
\hline TRPV4 & CCCGTGAGAACACCAAGTTT & GAAGAGCGTAATGACCTCGC & 374 \\
\hline TRPV5 & TTGCTCAGTTGCTGTCATCC & GCTCCTCTTTGTCGAACGTC & 307 \\
\hline TRPV6 & TCACTTCGCTTCCTGGAACT & ACACGCTTTCCACAAGCTCT & 401 \\
\hline GAPDH & GCTCTCTGCTCCTCCTGTTC & AAATCCGTTGACTCCGACC & 100 \\
\hline
\end{tabular}

Source: Invitrogen 
Online Repository Figure E1. Real time PCR (qRT PCR) expression of TRPV1 in fresh bronchial epithelial brush samples from healthy volunteers, mild/moderate asthmatics and severe asthmatics.

UK EPITHELIAL BRUSHINGS

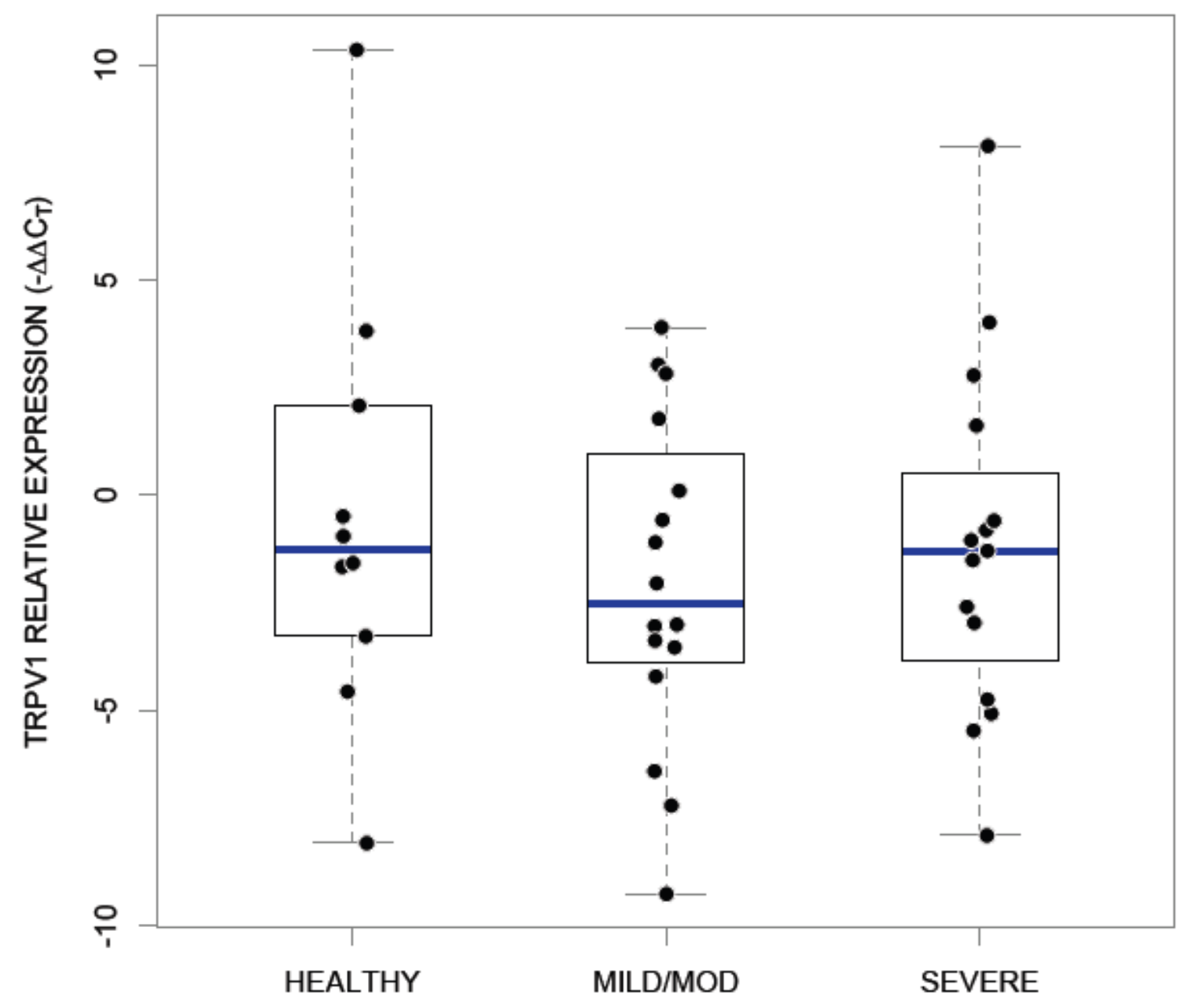

